\title{
Intervenções de Dragagem na Barra de Aveiro (Portugal) e de Protecção da Zona Costeira a Sul *
}

\section{Interventions to Dredge the Aveiro Bar (Portugal) and Improve Protection of the Coastal Area to the South}

\author{
T. L. Rosa ${ }^{1}$, A. Barata ${ }^{\circledR, 1}$, J. Geadas Cabaço $^{1}$, M. Teles ${ }^{1}$
}

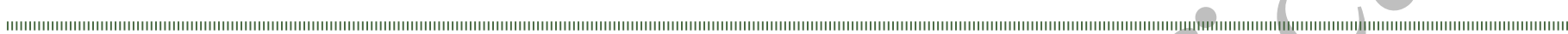

\section{RESUMO}

O presente estudo foi desenvolvido no âmbito do projecto de dragagem de cerca de $1 \times 10^{6} \mathrm{~m}^{3}$ de sedimentos na regiáo da barra de Aveiro (costa NW de Portugal), com obrigatoriedade de deposição no trecho costeiro a sul. Incluiu a determinação dos locais mais adequados para a realizaçáo dessas operaçóes, tanto de dragagem, como de depósito das areias, mantendo presente os seguintes objectivos: garantir que as condições de operacionalidade e de segurança da navegaçáo no acesso ao porto de Aveiro não fossem postas em causa pelo assoreamento na zona costeira exterior à barra e, ao mesmo tempo, acorrer à forte erosão costeira que se tem verificado no trecho a sul, entre a Costa Nova e o Areão. O estudo, que teve em consideração as condiçóes locais da hidrodinâmica do sistema e as características impostas pelo próprio projecto, foi realizado em 2005, para as autoridades portuguesas com compétências na área de intervenção: Instituto Portuário e dos Transportes Marítimos (IPTM), Administração do Porto de Aveiro (APA) e Instituto da Água (INAG). Foi entendido, por estas entidades, como um contributo fundamental para a gestáo costeira integrada da zona, constituindo um meio de apoio à tomada de decisão de actuação, a considerar na resolução dos problemas associados à situaçáo referida.

O presente artigo descreve a metodologia utilizada para definir os locaís de dragagem e deposição de areia, bem como os critérios utilizados na escolha da solução final. Numa primeira fase o estudo comportou uma compilaçấo e a análise de elementos hidrográficos existentes para a zona, de forma a melhor efectuar a caracterização do local em termos da evolução morfológica. Estes elementos constituíram a base da fase seguinte, destinada a analisar e a prever o comportamento morfodinâmico da zona, com avaliação das taxas de transporte sedimentar e teste das soluçóes alternativas de dragagem e de deposiçáo de areias. Nesta segunda fase recorreu-se à aplicação de um sistema de modelos matemáticos, com formulação bidimensional, que inclui a propagação da ondulação e da maré, as correntes induzidas pelas ondas e o transporte de sedimentos.

Numa fase final, a escolha da solução considerada como sendo a mais adequada resultou da aplicação de um método multi-critério de análise comparativa sobre sete possíveis soluçóes de dragagem e de deposiçẫo, na qual foram considerados não só critérios técnicos, mas também ambientais e económicos.

Palavras-chave: Modelação matemática, hidrodinâmica, transporte sedimentar, dragagem, gestão costeira integrada

@ - Autor correspondente: abarata@hidroprojecto.pt

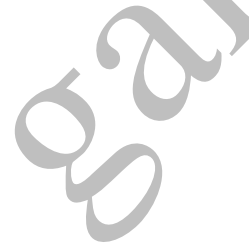

1 - Hidroprojecto, Engenharia e Gestäo S.A, Rua Quinta das Romeiras, 104, 1495-236 Algés, Portugal.

2 - Geosub, Prospecção Geomática e Ambiente, Lda., Estrada da Rebelva, Lote 2, 1ºD, 2775-371 Carcavelos, Portugal. 


\section{ABSTRACT}

The Aveiro coastal lagoon is located on the NW coast of Portugal. It is the largest Portuguese lagoon system which is permanently open to the sea. It is centred within a sand coastal section about $150 \mathrm{~km}$ long which has regular bathymetry, with bathymetric lines almost parallel along the coast. This regular pattern is only disturbed in the vicinity of the Aveiro Lagoon, which is connected to the ocean through a channel that provides shipping access to the port of Aveiro, located inside the lagoon.

The NW waves generated in the North Atlantic, by predominant N and NW winds, prevail near the NW Portuguese coast during almost $80 \%$ of the year. In the channel connecting the lagoon to the ocean, and in contrast to most of the Portuguese coast, the currents induced by the tide are very strong. Sometimes they can reach about $4 \mathrm{~ms}^{-1}$ at the entrance to the lagoon. Along the shoreline, off Aveiro bar, the currents are mainly southward during most of the year, with velocities about $0,5 \mathrm{~ms}^{-1}$, and tide reaches of about 2,85m during spring tide, and $1,25 \mathrm{~m}$ in neap tide conditions.

The ocean near the lagoon is characterised by an intense transport of mainly non-cohesive sediments, southwards along the shoreline. Since the 1950's the area has been subject to several interventions intended to improve shipping access to the port, including the construction of maritime protection structures. The main north breakwater at the entrance of the lagoon improved access by reducing sediment deposition in the navigation channel, but also interrupted the littoral drift, promoting sand deposition to the north of the north breakwater, and increasing erosion to the south of the entrance. After the northern zone became saturated, silting of the channel commenced. Several coastal protection works, along the coastline, have attempted to minimize this problem, including seawalls, groins, breakwaters, and dredging of the channel to guarantee the depths required for shipping.

The present study evaluated the most suitable sites for the dredging of $1000000 \mathrm{~m}^{3}$ of sand from the channel or surrounding area, as well as the deposit of the dredged material to the south of the lagoon entrance, in order to: guarantee safety and operability of the port of Aveiro; avoid silting-up of the coastal zone adjacent to the port entrance; and minimise erosion of the coastal areas to the south.

The study was performed in 2005, for the three authorities with jurisdiction over the coastal area of Aveiro Lagoon (IPTM - Institute of Ports and Maritime Transport; APA - Aveiro Port Administration and INAG - Portuguese Water Institute) and took into account the local hydrodynamic conditions and the characteristics and constraints of the project. It contributed significantly to coastal management in the area, since supports decision-making, conducting to the definition of an integrated solution for the situation referred to above.

This paper describes the methodology used to define the possible sites for dredging and deposition of the sand, as well as the criteria used to select the preferred solution.

Firstly, the available hydrographic information was analysed, in order to characterize the area and the bathymetric evolution of the sea bed. This information was then used to study the morphodynamic behaviour in the area, including estimating the sediment transport. Alternative sand dredging and deposition solutions were tested using a 2D hydrodynamic numerical model, including waves and tide propagation, currents induced by the waves and sedimentary transport.

Finally, the preferred solution was chosen using multi-criteria analysis for a comparative analysis of seven dredging and deposition solutions, considering technical, environmental and economic criteria. The final solution consists of dredging of $1000000 \mathrm{~m}^{3}$ of sand in the Aveiro bar entrance, between 9,0m and 12,5m depth, and the deposition of the dredged material in the sea to the south, in the submersed sector of the beach, between 2,0m and 5,0m depth, over an area between the third and fifth groins of Costa Nova.

Finally, the study recommended the development of a regular monitoring programme to take place after the project implementation, in order to objectively evaluate sedimentary and bed evolution over the dredged and deposition areas (beach and bed evolution).

The chosen solution was implemented by the competent authorities after 2008.

Keywords: Numerical modelling, hydrodynamics, littoral drift, dredging, integrated coastal zone management

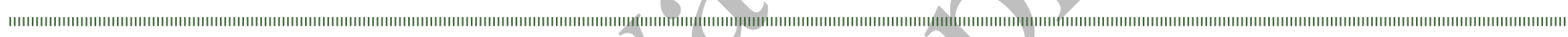

\section{INTRODUÇÃO}

\subsection{Enquadramento}

A zona costeira em estudo localiza-se na costa NW de Portugal, estando centrada aproximadamente no trecho litoral arenoso com cerca de $150 \mathrm{~km}$ de extensão, compreendido entre Espinho e o Cabo Mondego (figura 1). A batimetria costeira deste trecho é regular com batimétricas aproximadamente paralelas à linha de costa. Exceptua-se deste padrão, a proximidade da ligação da Ria de Aveiro ao oceano (403' $\left.40^{\prime \prime} \mathrm{N} ; 8^{\circ} 45^{\prime} 16^{\prime \prime} \mathrm{W}\right)$ efectuada através de um canal artificial fixado por dois molhes que permitem o acesso ao porto de Aveiro localizado precisamente já no interior da Ria.

A Ria de Aveiro constitui o maior sistema lagunar português com abertura permanente ao mar. A dinâmica desta laguna, que se caracteriza por uma geometria irregular, com canais estreitos, ao longo dos quais a propagação da maré induz a ocorrência de muitas zonas de espraiado, é muito complexa. A montante recebe inputs de água doce, principalmente do rio Vouga. A jusante, a embocadura constitui a zona de entrada da maré oceânica marcadamente do tipo semi-diurno regular.

Actualmente, a singularidade que a barra de Aveiro representa no trecho litoral está relacionada com o sistema de molhes e com a orientação e intensidade das correntes que estáo associadas ao prisma de maré da Ria, por sua vez definido em função da evolução da secção da barra e da amplitude de maré aí registada (Teixeira, 1994). De facto, e embora ao largo na costa ocidental de Portugal, face à influência dos ventos predominantes, as correntes de maré apresentem valores pouco significativos, as envolventes das embocaduras de rios e estuários, como é o caso da embocadura da Ria de Aveiro, constituem zonas de excepção, de forma 


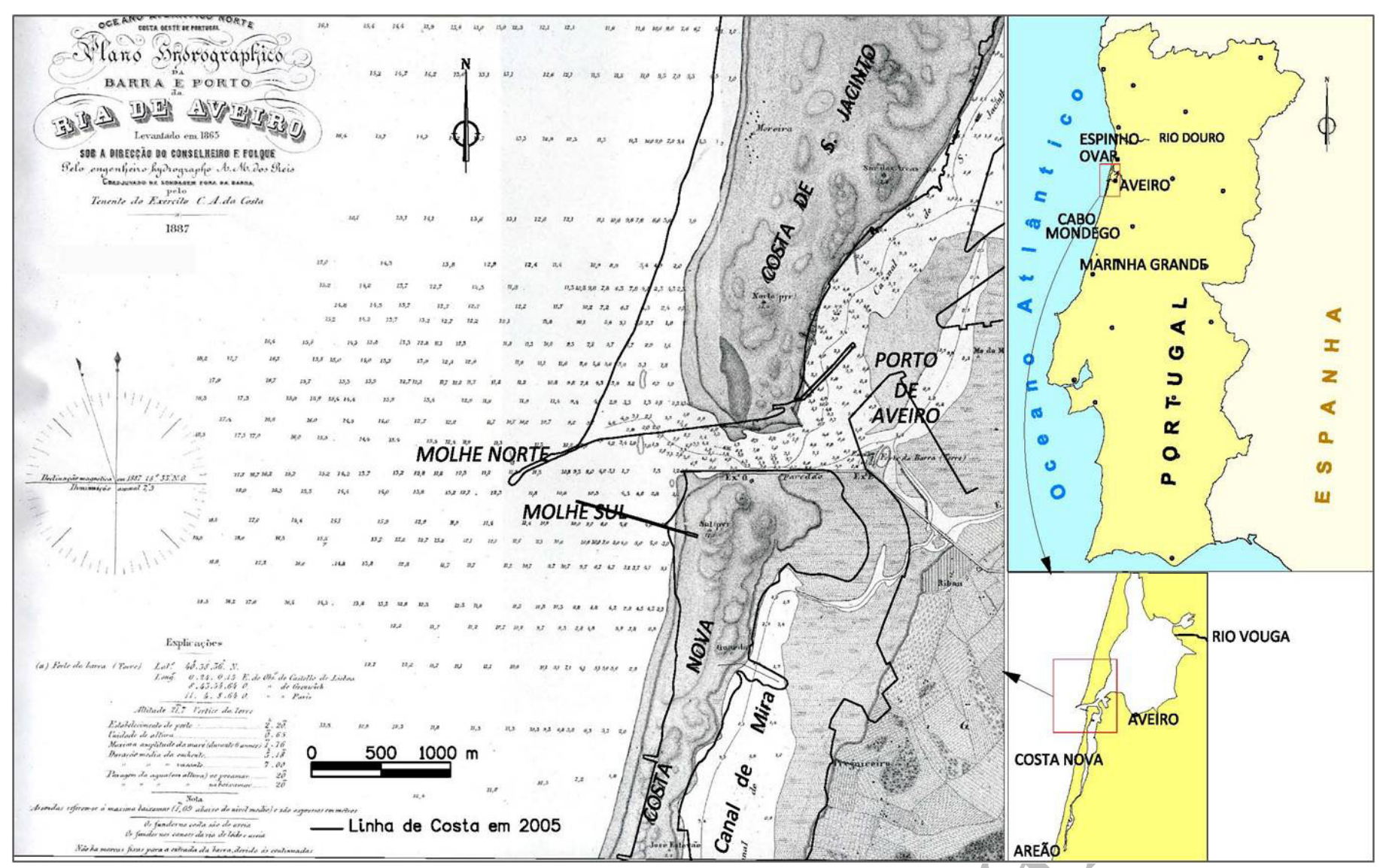

Figura 1. Zona costeira de Aveiro: comparação da linha de costa em 1887 e 2005 (Carta náutica no36403 - publicada pelo Instituto Hidrográfico). Figure 1. Aveiro coastal area: comparison of the coast line in 1887 and 1995 (Nautical chart no.36403-published by Portuguese Hydrographic Institute).

que, na vazante, em marés vivas, a corrente pode atingir os $3,1 \mathrm{~ms}^{-1}$, ou mesmo os $4,1 \mathrm{~ms}^{-1}$ em períodos de caudal mais acentuado (Instituto Hidrográfico, 1990). Na enchente os valores máximos são da ordem dos $2,1 \mathrm{~ms}^{-1}$. Fora da barra e até cerca de $5,5 \mathrm{~km}$ da costa, a corrente corre geralmente de norte para sul, não atingindo valores superiores a $0,5 \mathrm{~ms}^{-1}$ (Instituto Hidrográfico, 1990).

Valores publicados pelo Instituto Hidrográfico (2010) de Portugal permitem inferir valores das amplitudes de maré, ao largo de Aveiro, da ordem dos 2,72m (AV) e 1,28m (AM), referidas ao Zero Hidrográfico $(\mathrm{ZH})$, situado 2,0m abaixo no Nível Médio (NM) do mar.

A costa ocidental portuguesa, onde se insere a regiáo litoral de Aveiro, está muito exposta à ondulação gerada no Atlântico Norte e a agitação marítima na costa é caracterizada essencialmente por componentes de geração distante tendo, em geral, alturas e períodos superiores aos que ocorreriam por simples acção do vento local (Pires, 1989). As condiçôes de agitação marítima de NW são as mais frequentes na costa ocidental portuguesa, ocorrendo durante cerca de $80 \%$ do ano. Resultam da ondulação de NW gerada no Atlântico Norte em latitudes mais elevadas e da vaga associada aos ventos locais dominantes de N e de NW - mar do noroeste. A altura das ondas é superior a $1 \mathrm{~m}$ em cerca de $85 \%$ do ano e superior a $4 \mathrm{~m}$ durante cerca de $5 \%$ e $2 \%$ do ano (Pires, 1989).
A agitaçấo proveniente de SW ocorre principalmente no período de inverno e períodos de transição (Pires, 1989). São características do mar de SW as alturas de onda de $3 \mathrm{~m}$ a $4 \mathrm{~m}$ com períodos de $9 \mathrm{~s}$ a $10 \mathrm{~s}$, mas não é raro atingirem-se $7 \mathrm{~m}$ no caso de aproximaçóes frontais associadas a depressóes muito cavadas (Pires, 1989). No verão, o mar de sudoeste é pouco frequente e quando ocorre não excede em geral os $3 \mathrm{~m}$.

As ondas mais altas ocorrem preferencialmente durante $\mathrm{o}$ Inverno, quando a rama de rumos é mais larga e mais rodada a sul. O clima de agitação no verão é mais moderado e mais regular, predominando os rumos a norte de oeste (Teixeira, 1994). A altura média ao largo de Aveiro atinge $1,8 \mathrm{~m}$ e o período significativo associado ronda 11 s, conferindo a este litoral regime de elevada energia. A variação longilitoral da batimetria da praia submarina induz gradiente da altura ondulação na rebentação, que atinge valores médios da ordem de 1,7m em Espinho, até cerca de 2,0m no Cabo Mondego (Teixeira, 1994).

Às condições de ondulação de tempestade $(\mathrm{H}>5 \mathrm{~m})$ associam-se, regra geral rumos a norte do oeste, que ocorrem cerca de 10 dias por ano. Nestes períodos o montante de transferências sedimentares atinge $20 \%$ do total anual. A profundidade de acumulação da praia submarina recua para batimétricas inferiores a $5 \mathrm{~m}(\mathrm{ZH})$, possibilitando a ocorrência de rebentação de ondas na praia sub-aérea com alturas que excedem o limiar de manutenção do estado 
reflectivo, promovendo o rebaixamento generalizado do perfil da praia subaérea. Nessa altura, a estrutura de suporte de praia, a duna frontal, é tocada, eventualmente destruída (Teixeira, 1994).

No porto de Aveiro (no interior da Ria) o abrigo à agitação marítima é completo (Instituto Hidrográfico, 1990). Contudo, na zona exterior aos molhes da barra, a ondulaçáo do quadrante de W, de $\mathrm{N}$ a WSW, provoca frequentemente muita rebentação, obrigando ao encerramento da barra $(\mathrm{IH}$, 1990). A ondulação de $S$ e $S W$ é a mais benigna já que, em regra, não provoca o encerramento da barra.

Relativamente à ocorrência de temporais na costa portuguesa e considerando que nestas situaçóes a altura de onda significativa excede os $5 \mathrm{~m}$, Ferreira (1993), quantificou os períodos de retorno das ondas associadas aos temporais com uma duraçáo média de 4 a 5 dias. Os seus resultados apontaram para os seguintes valores: para uma altura significativa de $5 \mathrm{~m}$ os períodos mínimos de retorno dos temporais estarâo compreendidos entre 0,35 e 0,45 anos; para ondas de $8 \mathrm{~m}$ estes valores estarão no intervalo entre 1,1 e 2,1 anos; para alturas superiores a $12 \mathrm{~m}$ o período de retorno estará compreendido entre 5,3 e 32,0 anos.

$\mathrm{O}$ regime morfodinâmico, na embocadura da Ria de Aveiro é determinado pelo facto de esta se situar num trecho de costa aberta sujeito a intenso transporte longitudinal, cuja resultante anual é no sentido norte-sul. A construção do molhe Norte em 1953-55 resolveu, durante três décadas os problemas de navegabilidade na barra de Aveiro. Essa intervenção veio interromper a deriva litoral, correspondente ao caudal transportado pela ondulaçáo no sentido longilitoral que resulta da relaçáo de equilíbrio entre o clima de agitação marítima, os sedimentos disponíveis e a orientação do litoral exposto à ondulação vigente (Teixeira, 1994). Esta interrupção evitou que as areias continuassem a assorear a barra, mas provocou também forte deposição de areias imediatamente a norte do molhe e uma forte deficiência sedimentar a sul, onde se registou um recuo assinalável da linha de costa que pode ser visualizado na figura 1 .

Com o decorrer dos anos, o volume de areias acumulado na parte setentrional atingiu valores de saturação e o molhe Norte tornou-se menos eficaz na retençáo da deriva litoral, o que voltou a conduzir a um agravamento das condiçôes de navegabilidade na barra. $\mathrm{O}$ molhe Norte, voltou a ser prolongado 500m, entre 1983 e 1987, em paralelo com um conjunto de obras interiores de correcção dos canais, o que permitiu uma melhoria nas condiçôes de operacionalidade da barra. O banco exterior à barra foi sede de um desenvolvimento acelerado, e observou-se o agravamento, de forma significativa, dos problemas de erosão costeira a sul da Costa Nova (Dias et al., 1994).

Embora a erosão generalizada no trecho de costá tenha como causa principal o enfraquecimento das fontes aluvionares localizadas a norte, nomeadamente o rio Douro, não pode obliterar-se a influência que uma estrutura como o molhe Norte tem na escala local, na medida em que intercepta e altera localmente o padrão de transporte das areias.

Por outro lado, a minimização dos problemas referidos tem sido objecto de acções de protecção, nomeadamente com a realização de obras de defesa frontal, construção de esporóes (figura 3) ou execuçáo de dragagens nos canais de navegação destinadas a garantir as profundidades de serviço necessárias.

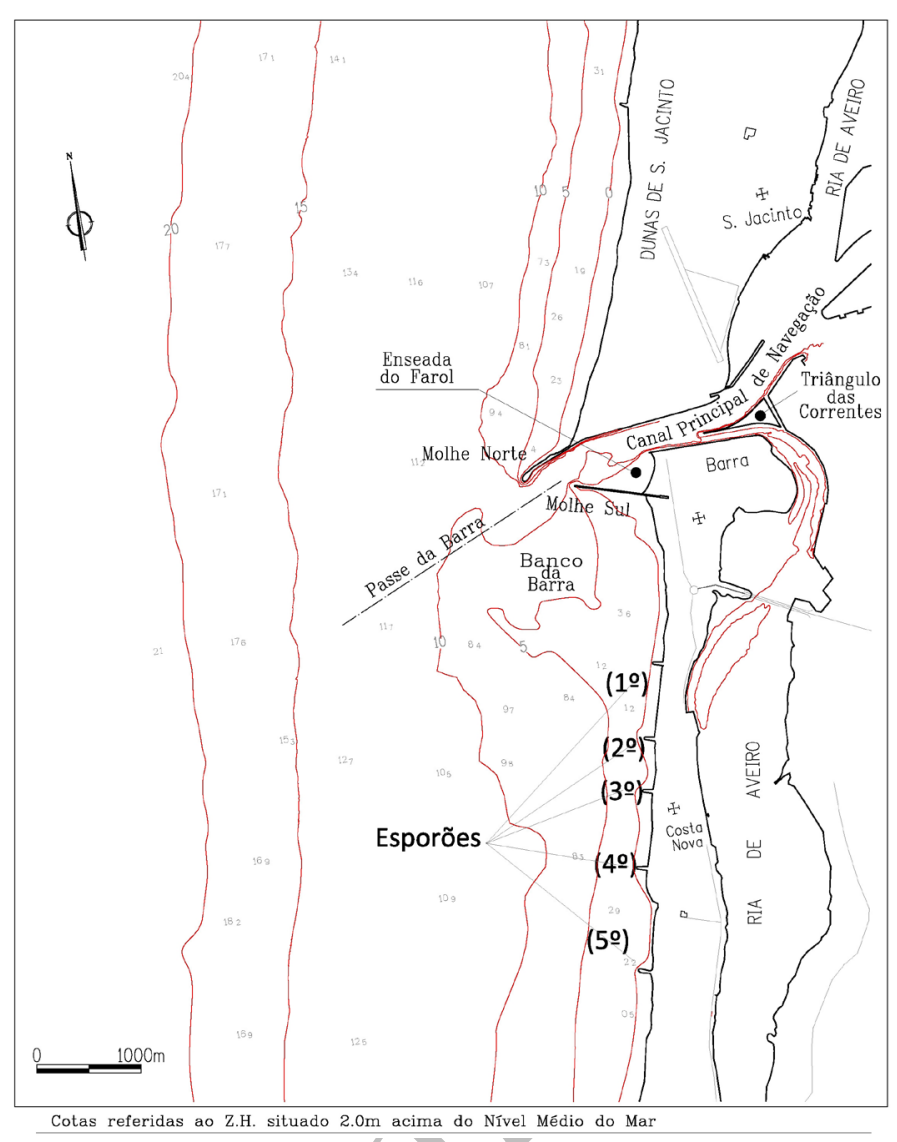

Figura 2. Área de estudo. Identificação das principais estruturas de protecção: cinco esporôes da Costa Nova

Figure 2. Study area. Identification of the main coastal protection works: five Costa Nova groins

\subsection{Objectivo}

Pretendendoassegurarqueascondiçóesdeoperacionalidade e a segurança da navegaçáo no acesso ao porto de Aveiro náo sejam postás em causa pelo assoreamento no exterior da barra de Aveiro e, ao mesmo tempo, acorrer à forte erosão costeira que se verifica no trecho a sul da barra, entre a Costa Nova e o Areão, preconizou-se que a realização da dragagem de cerca de $1 \times 10^{6} \mathrm{~m}^{3}$ de areia na regiáo da barra de Aveiro fosse efectuada por forma a que a sua posterior deposição pudesse contribuir para reforçar o trecho costeiro a sul. Neste sentido, em 2005, foi efectuado, para as autoridades portuguesas com competência no local (Instituto Portuário e dos Transportes Marítimos-IPTM / Administração do Porto de Aveiro-APA / Instituto da Água-INAG), um estudo que inclui cálculos de transporte sedimentar na zona costeira em análise, destinado, dentro das opçóes possíveis preconizadas para o projecto, a determinar quais os locais mais adequados de dragagem e deposiçâo de sedimentos, face às condiçóes hidrodinâmicas na zona (Hidroprojecto, 2006).

\subsection{Metodologia}

A definição das soluçôes para o problema colocado e a sua avaliação comparativa assentaram, quer na identificaçáo dos processos de acumulação de areia a norte do molhe 
Norte e dos processos erosivos no trecho a sul da barra, quer na simulação em modelo matemático transporte litoral da região da barra de Aveiro e dos trechos adjacentes. Numa primeira fase o estudo comportou a compilação e a análise de elementos hidrográficos existentes para a zona, de forma a actualizar a caracterização do local. Estes elementos constituíram a base da fase seguinte do estudo destinada a analisar e a prever o comportamento morfodinâmico da zona, suportada pela aplicação de um modelo matemático. A caracterização da zona, que envolveu a avaliação das taxas de transporte sedimentar bem como o teste das soluçóes alternativas de dragagem e deposição de areias efectuou-se com base na aplicação de um sistema de modelos matemáticos com formulaçâo bidimensional, constituído, basicamente, pelos três módulos seguintes, integrados no designado Sistema de Modelos da Ria e da Costa de Aveiro: propagação da ondulação; propagação da maré e de correntes induzidas pelas ondas; transporte de sedimentos.

Numa fase posterior, a escolha da solução final resultou da aplicação de um método multi-critério de análise comparativa das soluçốes de dragagem e de deposição estudadas, no qual foram considerados, não só critérios técnicos, mas também ambientais e económicos.

\section{ANÁLISE DE LEVANTAMENTOS HIDROGRÁFICOS E CARTOGRAFIA}

\subsection{Informaçáo batimétrica}

No âmbito da caracterização morfológica procedeu-se a uma análise da evolução hidrográfica da região da barra nas duas últimas décadas, incluindo a evolução da linha de costa. Neste sentido, uma primeira identificaçáo dos processos de acumulaçáo a norte e dos processos erosivos a sul resultou da compilação dos seguintes elementos hidrográficos existentes para a zona em estudo:

- Carta hidrográfica no33, publicada pelo Instituto Hidrográfico de Portugal (IH), em Abril de 1991, do Furadouro ao Cabo Mondego (aproximaçóes de Aveiro) à escala 1:75000. Segundo o diagrama de compilação associado, a informação contida nesta carta refere-se a: levantamento da barra e zona adjacente, efectuado em 1987 (1:5000); levantamento a norte do molhe Norte, efectuado em 1987 (1:25000); levantamento a sul da barra efectuado em 1987 (1:25000);

- Carta hidrográfica n59, publicada em Agosto de 1990 pelo IH, da Barra e Foz da Ria de Aveiro à escala 1:10000, com informaçáo hidrográfica extraída de levantamentos efectuados entre 1987 e 1988;

- Carta hidrográfica n²6403, publicada em Janeiro de 2005 pelo IH, da Costa Oeste, Aproximaçóes a Aveiro, à escala 1:30000, com informaçấo compilada, referida a: levantamento da zona da barra e do canal principal de navegação, de 2003; levantamento imediatamente a norte do molhe, junto à linha de costa, efectuado em 1987; levantamento imediatamente a sul do molhe sul, efectuado em 1987;

- Levantamento hidrográfico efectuado em Janeiro de 2003 no interior da ria, no canal entre S. Jacinto e a Torreira, à escala 1:1000, segundo a projecção de Gauss, Elipsóide Internacional, Datum 73;
- Levantamento hidrográfico do canal de navegação e da zona da barra, efectuado pela Administraçáo do Porto de Aveiro (APA) em Setembro de 2005 (1:5000).

A região caracteriza-se por uma acentuada dinâmica comprovada pelas marcadas diferenças batimétricas encontradas nestes elementos hidrográficos, alguns intervalados em mais de uma década. Os factores desta evolução incluem processos de assoreamento e de erosão e a realização, maisoumenosfrequente, deoperaçõesdedragagem, principalmente as associadas à manutenção das condições de operacionalidade do porto de Aveiro. Contudo e apesar dos elementos hidrográficos e cartográficos mencionados, é de referir que não foi possível fechar o balanço sedimentar na regiáo porque, no decurso da realização do trabalho não foi possível dispor de elementos relativos à evolução hidrográfica imediatamente a sul do banco da barra e do próprio sector sul do banco, nem de topografia actualizada do cordão dunar. Os elementos referidos permitiram, no entanto, efectuar a caracterização preliminar da evolução morfológica da zona tal como apresentada nos pontos seguintes.

\subsection{Trecho a norte da barra (S. Jacinto) - zona de acumulaçáo}

Genericamente na zona de intervençáo, e designadamente no trecho a norte da barra, o perfil topográfico da faixa da plataforma próxima é suavemente inclinado, aumentando progressivamente de pendor, sensivelmente a partir da batimétrica de $10 \mathrm{~m}$, à medida que se aproxima da praia. $\mathrm{A}$ zona a norte da barra de Aveiro constitui uma área com intenso processo de acumulaçáo sédimentar sendo o desalinhamento da linha de costa nos trechos a norte e a sul da barra de Aveiro, bem visível na figura 1. Porém, a comparação dos elementos hidrográficos disponíveis, de 1987 e de 2003, contidos respectivamente nas cartas hidrográficas n. ${ }^{\circ} 59$ e n. ${ }^{26403}$, permitiu inferir que, na zona imediatamente a norte da barra, no decurso desteperíodo, ocorreu um recuo de cerca de $120 \mathrm{~m}$ da isobatimétrica de $5 \mathrm{~m}$, em direcção à costa. Este facto poderá denotar um padrão erosivo, que engloba as vizinhanças do molhe Norte, que deverá ser encarado com alguma ressalva, na medida em que a zona da praia de S. Jacinto, durante o período considerado terá sido sujeita a opéraçôes de extracção de areia. A título exemplificativo refere-se que a extracção de areias da praia em S. Jacinto atingiu um valor de $590 \times 10^{3} \mathrm{~m}^{3} /$ ano em 1990 , e que entre 1994 e 1998 se manteve em cerca de 300 $\times 10^{3} \mathrm{~m}^{3} /$ ano (Cunha, 1998). Por outro lado, relativamente à evolução da própria linha de costa não é possível estabelecer comparaçóes, uma vez que o levantamento hidrográfico desse sector é o mesmo em ambas as cartas náuticas referidas, respectivamente, publicadas em 1990 e 2005.

\section{3 "Passe" da barra e banco da barra - zona de erosáo}

A comparação entre as situaçóes hidrográficas de 1987 e de 2003, mostradas, respectivamente, nas cartas náuticas publicadas em 1991 e 2005, revela um aumento das profundidades na barra e no sector norte do banco da Barra (único em que é possível a comparação). Em alguns locais a diferença de profundidades atinge $10 \mathrm{~m}$. $\mathrm{O}$ volume perdido por esse sector exterior aos molhes entre as duas situaçóes - 
intervaladas de 16 anos (1987-2003) - é cerca de $6,3 \times 10^{6} \mathrm{~m}^{3}$. Desse sector fazem parte a barra, os correspondentes sectores adjacentes a norte e a sul, e o sector norte do banco da barra. Este último sector perdeu $2,4 \times 10^{6} \mathrm{~m}^{3}$ e o sector da barra perdeu $3,9 \times 10^{6} \mathrm{~m}^{3}$.

Mais recentemente, entre 2003 e 2005, a comparação hidrográfica mostra uma diferença de $0,8 \times 10^{6} \mathrm{~m}^{3} \mathrm{com}$ aprofundamento na zona exterior centrada sobre o enfiamento da barra. No entanto, aquela diferença deverá ser analisada com prudência, visto que resulta da comparaçáo entre um levantamento hidrográfico e uma carta náutica. Como é sabido, no processo de construção da carta náutica apenas são seleccionadas as sondas mínimas de cada pequena área analisada. Da experiência, preconiza-se a aplicação de uma correcçáo de $0,6 \times 10^{6} \mathrm{~m}^{3}$ no caso vertente. Este valor da correcção resulta de se ter considerado que a carta náutica tem associada uma sobre-elevação média do fundo de $0,5 \mathrm{~m}$ no troço considerado, cuja área é 120 ha. Deste modo o volume de erosão a considerar é $0,2 \times 10^{6} \mathrm{~m}^{3}$.

\subsection{Trecho final do canal de navegação - zona de erosáo}

As comparaçóes hidrográficas do troço do canal de navegação entre a secção da base do Triângulo das Correntes e a secção entre as cabeças dos molhes Norte e Sul apuraram as seguintes diferenças de volumes: entre 1987 e 2003, perda de $3,2 \times 10^{6} \mathrm{~m}^{3}$ (aprofundamento); entre 2003 e 2005, perda de $1,0 \times 10^{6} \mathrm{~m}^{3}$ (aprofundamento).

$\mathrm{O}$ volume apurado na primeira comparação, efectuada entre duas cartas náuticas, é coerente com o esforço de extracção de areias registado entre 1987 e 1998 no canal de navegação, que se estima em cerca de $3,6 \times 10^{6} \mathrm{~m}^{3}$, segundo dados da APA, referidos eventualmente a um troço de canal ligeiramente mais extenso.

À semelhança do que foi preconizado para a comparação hidrográfica na zona exterior aos molhes, a diferença apurada na segunda comparação terá de ser analisada à luz da incoerência entre o levantamento hidrográfico e as sondas representadas na carta náutica. Pela razão atrás referida haverá que aplicar uma correcção de cerca de $0,3 \times 10^{6} \mathrm{~m}^{3}$ à diferença obtida. O referido valor resulta de se ter considerado que a carta náutica tem associada uma sobre-elevaçáo média do fundo de $0,5 \mathrm{~m}$ no troço considerado, cuja área é 70 ha. Por outro lado, uma análise da distribuição espacial das diferenças mostra que estas se concentram na enseada do Farol - onde foi removido um cabeço de areia - e na área terminal do canal de navegação, principalmente na proximidade da cabeça do molhe Norte. A estas áreas corresponde só por si, a diferença igual a $0,7 \times 10^{6} \mathrm{~m}^{3}$, correspondente a um aprofundamento.

$\mathrm{O}$ aumento das profundidades sobre o banco da barra e na própria barra dá origem a maior exposiçẩo da costa imediatamente a sul do molhe Sul. Este facto eventualmente poderá constituir um factor que favoreça o aparecimento localizado de fenómenos erosivos junto à costa.

\subsection{Sub-trecho a sul do molhe sul - zona de acumulaçáo}

Embora não existindo elementos topográficos e hidrográficos para comparação com a situação de 1987 , estima-se, com base na inspecção do trecho e na recolha de informaçóes no local, que o sub-trecho de $3 \mathrm{~km}$ que se desenvolve a partir do molhe Sul tenha engrossado, até à data do trabalho, cerca de $4 \mathrm{~m}$ sobre uma largura de $300 \mathrm{~m}$. De facto, houve desmonte da defesa frontal de emergência de protecção às casas do núcleo urbano da Barra situadas para sul da raiz do molhe sul, por desnecessária, reforçandose a praia nesse sector. A posição daquela estrutura pode ser referenciada nas cartas náuticas de 2005 que, curiosamente, mantiveram a sua representação. Por outro lado, verificou-se uma recriação significativa, da ordem da centena de metros, dos sectores sub-aéreos das praias da Costa Nova entre os $1^{\circ}$ e $2^{\circ}$, e o $2^{\circ}$ e o $3^{\circ}$ esporóes e, em menor grau, entre os $3^{\circ} \mathrm{e}$ $4^{\circ}$ esporóes da Costa Nova.

Constitui igualmente um traço a assinalar na hidrografia da zona, representada nas cartas náuticas, a existência de duas flechas formadas em frente à Costa Nova, de sentido sul-norte, que estarão associadas aos processos de refracção e de difracçáo pelo fundo produzidos pelo banco da barra.

\subsection{Trecho sul - zonas de erosão}

Ao contrário da tendência para acumulação no sub-trecho atrás referido, a costa a sul do $4^{\circ}$ esporão dá Costa Nova tem vindo a ser sede de processos erosivos que, em alguns locais e épocas, têm sido muito intensos. A sul do $4^{\circ}$ esporão, por exemplo, houve necessidade de construir uma defesa frontal de emergência. Esta estrutura mantém-se activa, apesar da existência do $5^{\circ}$ esporáo, que continua praticamente todo dentro de água, sendo também ténues as tendências de retenção de areias na sua face norte.

Por sua vez, na zona costeira a sul do $5^{\circ}$ esporão é de referir, a título de exemplo, que uma inspecção local efectuada em 2004, revelou uma situação envolvendo risco eminente de rotura do cordáo dunar, particularmente preocupante na zona da praia do Areão e nas suas vizinhanças, (Plecha, 2004). Nesta zona, a construção do esporão do Areão, efectuada anteriormente, entre 2002 e 2003, apesar de ter colmatado localmente o problema, com a criação de uma retençâo e acumulaçấo visível de areia na sua face norte, não o resolveu inteiramente.

\section{DEFINIÇÁO PRELIMINAR DE LOCAIS DE DRAGAGEM E DEPOSIÇÁO}

A partir da caracterização apresentada sobre a acumulação de areia a norte do molhe Norte e os processos erosivos a sul, e considerando as características do projecto, limitado a um volume de dragagem igual a $1 \times 10^{6} \mathrm{~m}^{3}$, foi efectuada uma análise envolvendo critérios técnicos, ambientais e económicos. Esta análise conduziu, numa fase preliminar, e em conjunção com a identificação dos métodos apropriados de dragagem e de deposição, à formulação de um conjunto de sete soluçóes alternativas, referidas nas tabelas 1 e 2 e localizadas na figura 3 . 
Tabela 1. Identificação dos locais de dragagem propostos.

Table 1. Description of proposed dredging sites.

\begin{tabular}{ll}
\hline \multicolumn{3}{c}{ LOCAIS DE DRAGAGEM } \\
\hline \multirow{2}{*}{ NORTE } & $>$ Trecho de $1500 \mathrm{~m}$, em frente da praia de $\mathrm{S}$. Jacinto entre as batimétricas de $3 \mathrm{~m} \mathrm{e} 7 \mathrm{~m} ;$ \\
& $>$ Volume $=1,0 \times 10^{6} \mathrm{~m}^{3}$. \\
\hline \multirow{2}{*}{ BANCO } & $>$ Área de 70 ha no banco da barra, entre as batimétricas de $3 \mathrm{~m}$ e $5 \mathrm{~m} ;$ \\
& $>$ Volume $=1,0 \times 10^{6} \mathrm{~m}^{3}$. \\
\hline \multirow{2}{*}{ BARRA } & $>$ Área de 120 ha centrada sobre o enfiamento da barra, entre as batimétricas de 9,0 e $12,5 \mathrm{~m} ;$ \\
& $>$ Volume $=1,0 \times 10^{6} \mathrm{~m}^{3}$. \\
\hline
\end{tabular}

Tabela 2. Identificação dos locais de depósito propostos.

Table 2. Description of proposed sites for sand deposit.

\section{LOCAIS DE DEPOSIÇÃO}

A1. Trecho no mar entre os terceiro e quarto esporóes da Costa Nova, no sector submerso da praia, entre as batimétricas de $2 \mathrm{~m}$ e $5 \mathrm{~m}$; volume $=0,5 \times 10^{6} \mathrm{~m}^{3}$.

A

A2. Trecho no mar entre os quarto e quinto esporốes da Costa Nova, no sector submerso da praia entre as batimétricas de $2 \mathrm{~m}$ e $5 \mathrm{~m}$; volume $=0,5 \times 10^{6} \mathrm{~m}^{3}$.

B1. Trecho no mar entre os quarto e quinto esporóes da Costa Nova a sul da obra aderente, no sector submerso da praia entre as batimétricas de 2 e $5 \mathrm{~m}$; volume $=0,5 \times 10^{6} \mathrm{~m}^{3}$.

B2. Trecho em terra, na duna, entre os quarto e quinto esporôes da Costa Nova a sul da obra aderente; volume $=0,5 \times 10^{6} \mathrm{~m}^{3}$.

C1. Trecho de $1000 \mathrm{~m}$ no mar a sul do quinto esporão da Costa Nova; no sector submerso da praia entre as batimétricas de C $2 \mathrm{~m}$ e $5 \mathrm{~m}$; volume $=0,5 \times 10^{6} \mathrm{~m}^{3}$.

C2. Trecho de $1000 \mathrm{~m}$ em terra, na duna, a sul do quinto esporão da Costa Nova; volume $=0,5 \times 10^{6} \mathrm{~m}^{3}$.

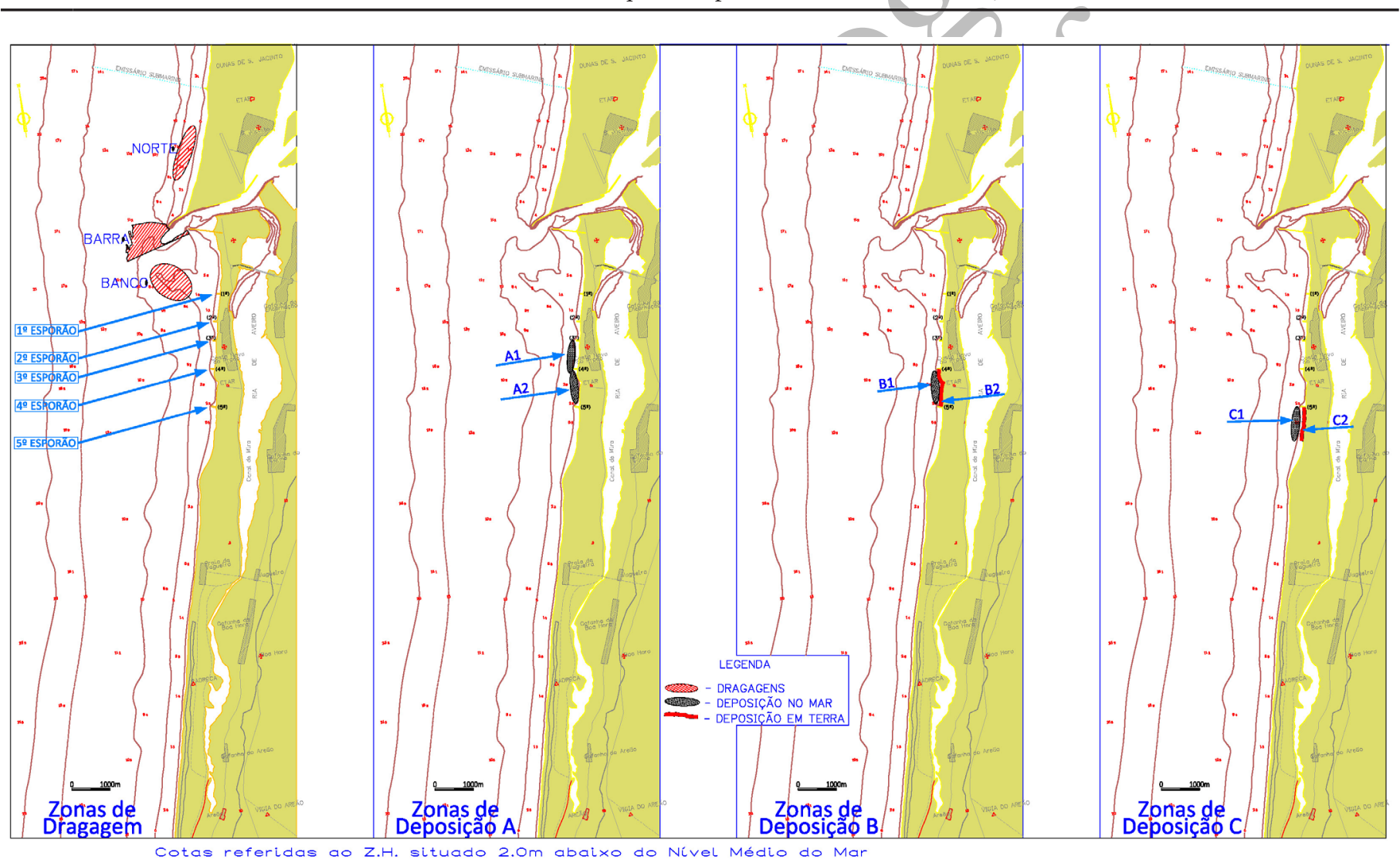

Figura 3. Localização dos locais propostos para dragagem e depósito de $1 \times 10^{6} \mathrm{~m}^{3}$ de areias.

Figure 3. Sites proposed for dredging and deposition of $1 \times 10^{6} \mathrm{~m}^{3}$ of sand. 


\section{MODELAÇÃO MATEMÁTICA}

Os processos sedimentares e a sua interacção com a morfologia foram estudados recorrendo a metodologias de modelaçáo matemática utilizada para caracterizar uma situação de referência e complementar a análise das soluções de dragagem e as que envolveram, especificamente, depósito no mar.

\subsection{Fundamentos do modelo matemático}

O transporte sedimentar, sendo função da acção combinada das ondas e das correntes de maré e da sua interacção com o fundo, constitui um processo complexo, passando a metodologia da sua análise pelo recurso à modelaçáo matemática. No caso particular das zonas onde a batimetria e o escoamento apresentam padrōes marcadamente bidimensionais, como na proximidade das embocaduras, pode recorrer-se a uma formulação bidimensional para estudar o transporte dos sedimentos. Desta forma, a caracterização do comportamento morfodinâmico da zona, com avaliação das taxas de transporte sedimentar bem como o teste das soluçóes alternativas de dragagem e deposição de areias efectuou-se com base no desenvolvimento de um sistema de modelos matemáticos 2D, designado por Sistema de Modelos da Ria e da Costa de Aveiro (Teles \& Barata, 1996; Hidroprojecto, 2001) constituído, basicamente, pelos três módulos de: propagação da ondulação, propagação da maré e de correntes induzidas pelas ondas e transporte de sedimentos.

Uma breve descrição destes módulos, aplicados sucessivamente pela ordem indicada, é apresentada seguidamente.

\subsection{Módulo de propagaçáo da ondulaçáo}

$\mathrm{O}$ módulo de propagação da ondulaçáo que integra o Sistema de Modelos da Ria e da Costa de Aveiro resolve a equação da conservação da energia das ondas em associação com uma relação de dispersão, linear ou não. A equação original elíptica, designada por equação de "mild slope" é transformada numa equação parabólica conduzindo a métodos de resolução numérica muito eficientes, com a consequente redução do tempo de cálculo. O método de resolução das equações é de diferenças finitas. Os algoritmos de cálculo recorrem ao esquema de Crank-Nicholson e a outros esquemas implícitos.

$\mathrm{O}$ modelo considera que as ondas se propagam quasiunidireccionalmente e que a onda reflectida é desprezável. Este último aspecto não constitui uma limitação à aplicaçáo ao domínio em estudo, uma vez que, dada a escala envolvida, o efeito dos fenómenos de reflexáo se pode considerar desprezável. Considera os efeitos da refracçáo e da difracção, numa malha regular, que se pode construir idêntica ou igual à do módulo de propagação da maré. Além dos efeitos mencionados, são incluídos os efeitos de dissipaçáo por atrito no fundo, sob a forma de turbulência na zona de rebentação, o que o torna uma versão bastante completa para aplicação em zonas costeiras e na presença de embocaduras.

As condições de fronteira do modelo de propagação da ondulação no Sistema de Modelos da Ria e da Costa de
Aveiro são especificadas a partir do tratamento dos dados de agitação marítima. Para cada simulação são atribuídos, ao longo da fronteira oeste, os valores relativos aos parâmetros que caracterizam a ondulação: altura significativa, período e rumo da onda. Os valores nas fronteiras norte e sul são calculados pelo próprio modelo a partir dos anteriores.

\subsection{Módulo de propagaçáo da maré e de correntes induzidas pelas ondas}

O módulo de propagação da maré e das correntes induzidas pelas ondas tem formulação bidimensional no plano horizontal. Da integração segundo a direcção vertical resulta que as equaçóes que constituem o modelo (equação de Navier-Stokes, da continuidade do volume e do balanço de massa) são resolvidas em termos das variáveis de campo na coluna de água. O método numérico é de diferenças finitas, semi-implícito, de duplo varrimento e direcçóes alternantes, ADI. O modelo assenta no algoritmo desenvolvido por Leendertse (1987).

São representados pelo modelo os fenómenos mais importantes que intervêm na propagaçấo da maré e na transferência da energia do vento para a água, designadamente: a advecção da quantidade de movimento, o atrito no fundo, o atrito lateral devido à difusâo horizontal da quantidade de movimento, a força tangencial do vento à superfície, o efeito de rotaçáo da Terra (efeito de Coriolis) e os gradientes de pressão do modo barotrópico.

Por outro lado o modelo integra, na equação de NavierStokes, um termo adicional relativo às correntes induzidas pelas ondas, calculado em cada célula do domínio de cálculo a partir de gradientes das tensóes de radiação, calculados, por sua yez, em função da altura, período e direcção da onda fornecidos pelo módulo de propagação da ondulação, descrito no ponto anterior. Este procedimento corresponde a considerar as correntes induzidas por um campo de ondas estacionário, associado a uma determinada condição de ondulação áo largo, que se mantém constante durante, pelo menos, um intervalo de tempo da mesma ordem de grandeza do período da maré.

O modelo de propagaçáo da maré e das correntes induzidas pelas ondas permite calcular alturas de água e as velocidades totais à custa de alturas e direcçóes locais da onda e de condiçôes fronteira de maré ou velocidade.

\subsection{Módulo de transporte de sedimentos}

O módulo de transporte sedimentar do Sistema de Modelos da Ria e da Costa de Aveiro considera o transporte de sedimentos não coesivos. As partículas simuladas podem variar, quer em dimensão, quer em constituição. Considerouse que o material predominante é o quartzo e que a dimensão dos grãos corresponde a areia, isto é, o diâmetro mediano varia tipicamente entre $0,1 \mathrm{~mm}$ e $0,5 \mathrm{~mm}$ (Hidroprojecto, 1994; Hidroprojecto, 2007). Estas partículas têm velocidades de queda relativamente elevadas, da ordem de $2 \mathrm{~cm} / \mathrm{s}$ e, consequentemente, possuem tempos de suspensão muito curtos, ao contrário dos sedimentos coesivos que são transportados em suspensão a grandes distâncias. O transporte dos sedimentos não coesivos depende principalmente do balanço local de forças, que se traduzem por correntes devidas 
à propagação da maré e induzidas pelas ondas. Na camada de fundo, os sedimentos são levantados pela acção combinada da rugosidade e da tensão de corte exercida junto ao fundo, por sua vez, também devida, sobretudo, às ondas.

No Sistema de Modelos da Ria e da Costa de Aveiro o módulo do transporte de sedimentos baseia-se na determinação das taxas de transporte médias referidas ao período da onda, em funçáo das características locais e instantâneas do escoamento, constituído por correntes e ondas. Para o cálculo das taxas de transporte optou-se pela utilização do método de Van Rijn (1989), que considera a acção conjugada de correntes e ondas. O método é susceptível de ser aplicado fora e dentro da rebentação o que o torna particularmente apropriado à determinação da acção de correntes fortes em presença de ondas, tal como a zona do banco da barra de Aveiro, onde as correntes fortes se devem, quer à acção da maré na vizinhança da barra, quer às correntes na zona de rebentação, induzidas pelas ondas ao longo da costa.

\subsection{Condiçóes de simulaçáo}

\subsubsection{Dominio de Cálculo}

As equaçôes que constituem os vários módulos do Sistema de Modelos da Ria de Aveiro são resolvidas num domínio de cálculo, representado na figura 4. Este domínio, com uma malha regular de $50 \mathrm{~m}$, representa toda a regiáo lagunar, incluindo a parte terminal do rio Vouga, numa extensão total de 40,5km segundo $y$ e $15,4 \mathrm{~km}$ segundo $x$. O eixo $y$ do domínio faz um ângulo de $15^{\circ} \mathrm{com}$ o Norte real, no sentido ciclónico. Esta orientaçáo permite uma melhor reprodução da dinâmica do sistema, tanto nos canais da ria, como na zona costeira, na medida em que a malha fica aproximadamente orientada com as linhas batimétricas do sistema.

A elaboração do domínio descrito resultou da utilização de informação hidrográfica da região, nomeadamente a referida no ponto 2.1 da presente publicação. $\mathrm{O}$ mesmo domínio de cálculo é utilizado para os modelos de propagação da ondulação, propagação da maré e de correntes induzidas pelas ondas e do transporte de sedimentos. Os fundamentos da calibraçáo do modelo efectuada a partir de observaçôes anteriormente realizadas em vários pontos da Ria de Aveiro encontram-se descritos em Hidroprojecto (2001).

\subsubsection{Condiçóes fronteira de agitaçáo marítima: ondas representativas}

Representam-se na tabela 3 as seis ondas representativas do clima de agitação marítima, utilizadas nas simulaçóes do transporte sedimentar.

$\mathrm{O}$ processo que conduziu à selecção destas ondas encontra-se descrito em Barata et al. (1996) onde pode, igualmente, ser encontrada uma descriçáo pormenorizada do clima de agitação da região da barra de Ayeiro. A determinação das ondas referidas resultou de uma análise conjunta da distribuição dos parâmetros da agitação e da respectiva frequência de ocorrência, optando os referidos autores por seleccionar as ondas dominantes, do ponto de vista do transporte anual de sedimentos, em vez das ondas predominantes de um ponto de vista meramente estatístico, restrito aos parâmetros da onda.

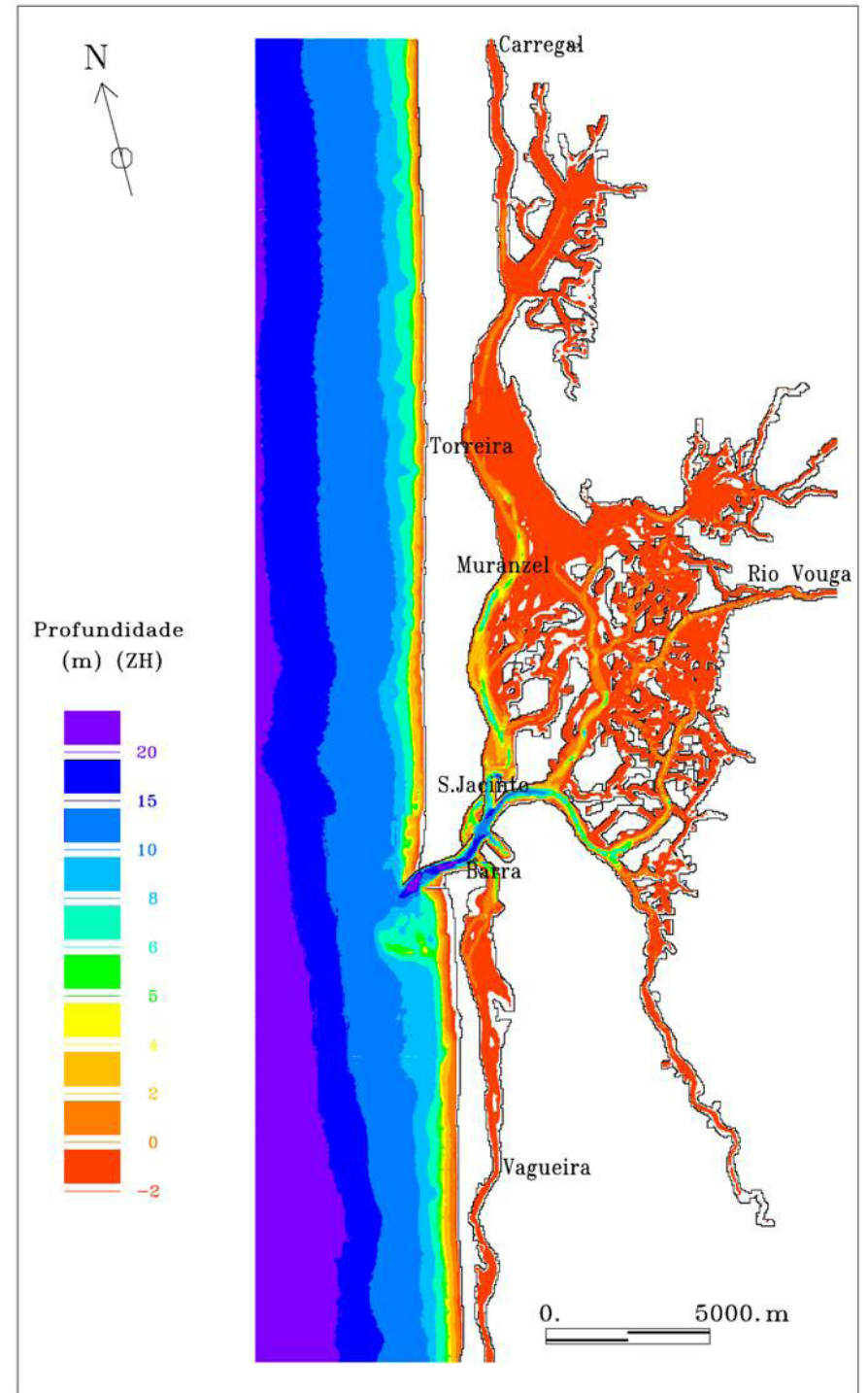

Figura 4. Domínio de simulaçáo.

Figure 4. Numerical model domain.

Tabela 3. Ondas representativas da agitaçáo marítima seleccionadas para a simulaçáo do balanço anual de transporte de sedimentos da costa de Aveiro - dados de 1992 (Barata et al., 1996).

Table 3. Representative waves select for the simulation of the yearly littoral sediments transport in the Aveiro coast - 1992 data (Barata et al., 1996).

\begin{tabular}{c|c|c|c|c}
\hline Ondas & Altura (m) & Período $(\mathbf{s})$ & Rumo (o) & Frequência (\%) \\
\hline 1 & 1,75 & 12 & 315,00 & 50,00 \\
\hline 2 & 2,25 & 12 & 303,75 & 30,02 \\
\hline 3 & 3,75 & 12 & 326,25 & 9,80 \\
\hline 4 & 4,75 & 15 & 315,00 & 1,64 \\
\hline 5 & 6,25 & 15 & 315,00 & 1,00 \\
\hline 6 & 3,75 & 12 & 281,25 & 7,54 \\
\hline
\end{tabular}


O critério de selecção das ondas representativas foi estabelecido recorrendo ao cálculo do transporte litoral num perfil transversal numa zona de batimetria regular, isto é, afastada das embocaduras. As condiçóes foram seleccionadas tendo por base o princípio que, ao longo dum perfil transversal, devem produzir o mesmo transporte anual e a mesma distribuição que o conjunto das ondas que representam o clima de agitaçáo, cujo transporte e distribuição foram previamente calculados nesse perfil (Barata et al., 1996).

As ondas seleccionadas, apresentadas na tabela 3, constituem não só as condições de fronteira dos modelos de propagação da ondulação e das correntes induzidas pelas ondas, utilizados para caracterizar a dinâmica costeira, mas também as condições para a simulação do balanço anual do transporte de sedimentos não coesivos.

\subsubsection{Condiçóes de fronteira e iniciais dos módulos hidrodinâmico e de transporte sedimentar}

No modelo de propagação da maré são especificadas séries temporais de alturas de água nas fronteiras norte, leste e sul. Ao longo da fronteira oeste foi introduzido um desfasamento de modo a representar o efeito regional da componente da propagação da maré, de sul para norte. $\mathrm{Na}$ direcção perpendicular à costa foram introduzidas correcções à inclinação da superfície livre, para incluir os efeitos, quer da sobre-elevação devida à propagação da ondulação, quer do vento. A aplicação presente não considerou, no entanto, a acção do vento. $\mathrm{Na}$ fronteira Este considerou-se suficiente a especificação de uma única condição de caudal médio igual $5 \mathrm{~m}^{3} / \mathrm{s}$.

O modelo de propagação da maré e de correntes induzidas pelas ondas correu com uma condiçáo fronteira de maré reproduzida na figura 5 .

Como resultado obtiveram-se valores de alturas de água e de correntes, a ser posteriormente utilizados no cálculo do transporte sedimentar, como campos iniciais de níveis de água e velocidade, para arranque do modelo.

$\mathrm{O}$ modelo de transporte sedimentar correu com um intervalo de acumulação, no total, igual a um período de maré (12h 25min).
Relativamente às ondas considerou-se que a escala temporal relevante seria o ano, esquematizado pelo número de condiçôes características de agitação ao largo, referidas como ondas representativas. Para o conjunto de simulaçóes efectuadas, tomaram-se ainda os sedimentos com um diâmetro médio de $0,25 \mathrm{~mm}$, associado ao quartzo.

\section{RESULTADOS E DISCUSSÁO DA APLICAÇÁO DO MODELO MATEMÁTICO}

A aplicação do Sistema Bidimensional de Modelos da Ria e da Costa de Aveiro resultou na definiçẫo da caracterização de uma situação de referência e das várias soluções destinadas à prossecução dos objectivos fundamentais do projecto. Os resultados obtidos, que permitiram determinar taxas de transporte sedimentar potencial na região, são descritos nos pontos seguintes.

\subsection{Situaçáo de referência}

\subsubsection{Propagaçáo das ondas}

A batimetria complexa conduz a alteraçoes significativas na propagação da ondulação e ao longo da costa observase a alternância de zonas de convergência e de divergência, tal como pode ver-se, a título de exemplo, na figura 6 , que representa um resultado do modelo de propagação das ondas. Nesta figura está representado o campo relativo à direcção local da propagaçâo da onda 4 (ver tabela 3 ) e ao coeficiente de refracçâo-diffacçáo, definido pelo coeficiente entre a altura da onda registada em cada célula da malha de cálculo e o valor dá altura de onda em água profunda.

Verifica-se que as principais perturbações na propagação da ondulaçáo se registam na zona da barra e do banco da barra. Sobre o banco da barra é gerada uma zona de convergência muito significativa, à qual está associado um aumento local da altura da onda. Imediatamente a sul desta zona, verifica-se uma diminuiçáo da altura da onda, associada a uma divergência da ondulação. Em consequência do abrigo proporcionado pelos molhes Norte e Sul identifica-se uma zona de difracçấo com forte diminuiçáo da altura da onda junto à zona sul do molhe Sul. Uma análise segundo uma
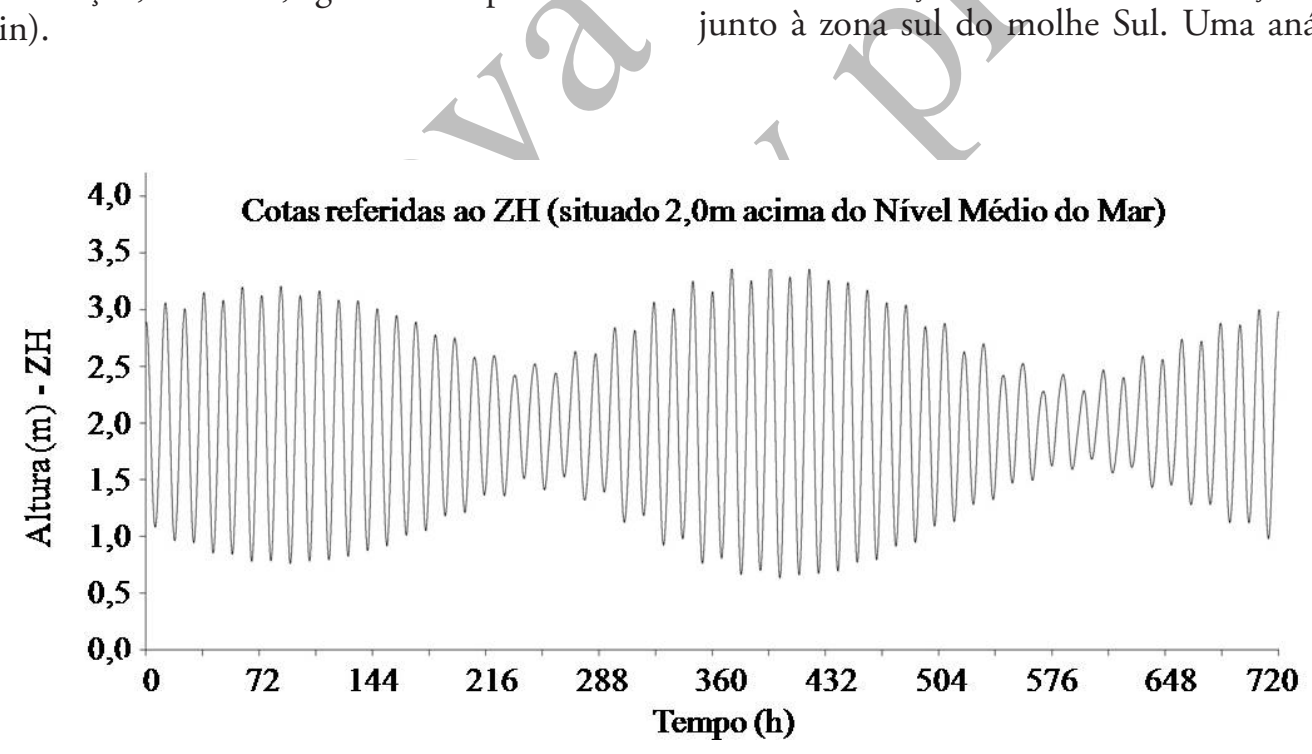

Figura 5. Condição fronteira da maré do modelo matemático.

Figure 5. Numerical model tidal boundary condition. 
direcção transversal à costa mostra que para as ondas de maior altura (ondas 4 e 5), a zona de rebentaçáo se posiciona mais ao largo do que as restantes ondas. Este aspecto é particularmente visível sobre o banco da barra no caso da propagação da onda 4 (figura 6).

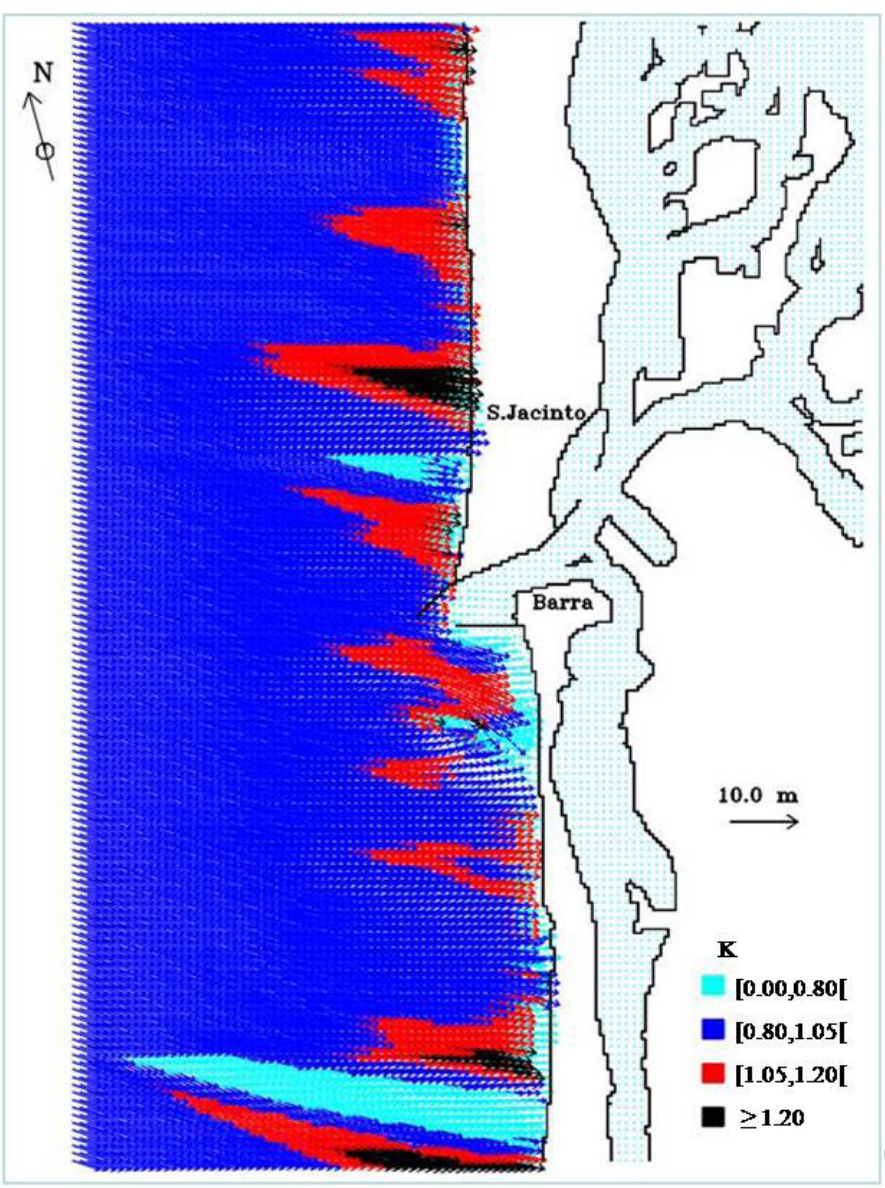

Figura 6. Resultado do modelo de propagação da ondulação para a onda $4 \quad\left(\theta=315^{\circ} ; \mathrm{T}=15 \mathrm{~s} ; \mathrm{H}=4,8 \mathrm{~m}\right)$. K: coeficiente de refracção-difracção.

Figure 6. Model result of wave 4 propagation $\left(\theta=315^{\circ} ; T=15\right.$; $H=4,8 m)$. K: refraction-diffraction coefficient.

\subsubsection{Velocidade da corrente}

O aspecto mais significativo dos resultados obtidos (figura 7) refere-se à importância do jacto de vazante através da barra na definição do padrão de velocidades na zona adjacente, constituída pelo sistema da barra, molhes e banco da barra. Associado ao jacto de vazante instala-se uma circulaçáo residual de sentido anticiclónico, pelo norte do enfiamento da barra. Como consequência deste padrão, a corrente junto à cabeça do molhe Norte tem o sentido da enchente em qualquer fase da maré. Este fenómeno poderá potenciar a transposição de areias de norte para sul nesse local.

\subsubsection{Transporte anual}

Os resultados de alturas, direcçóes e tensôes de radiação das ondas obtidos na simulação com o modelo de propagação das ondas foram incorporados no modelo de propagação da

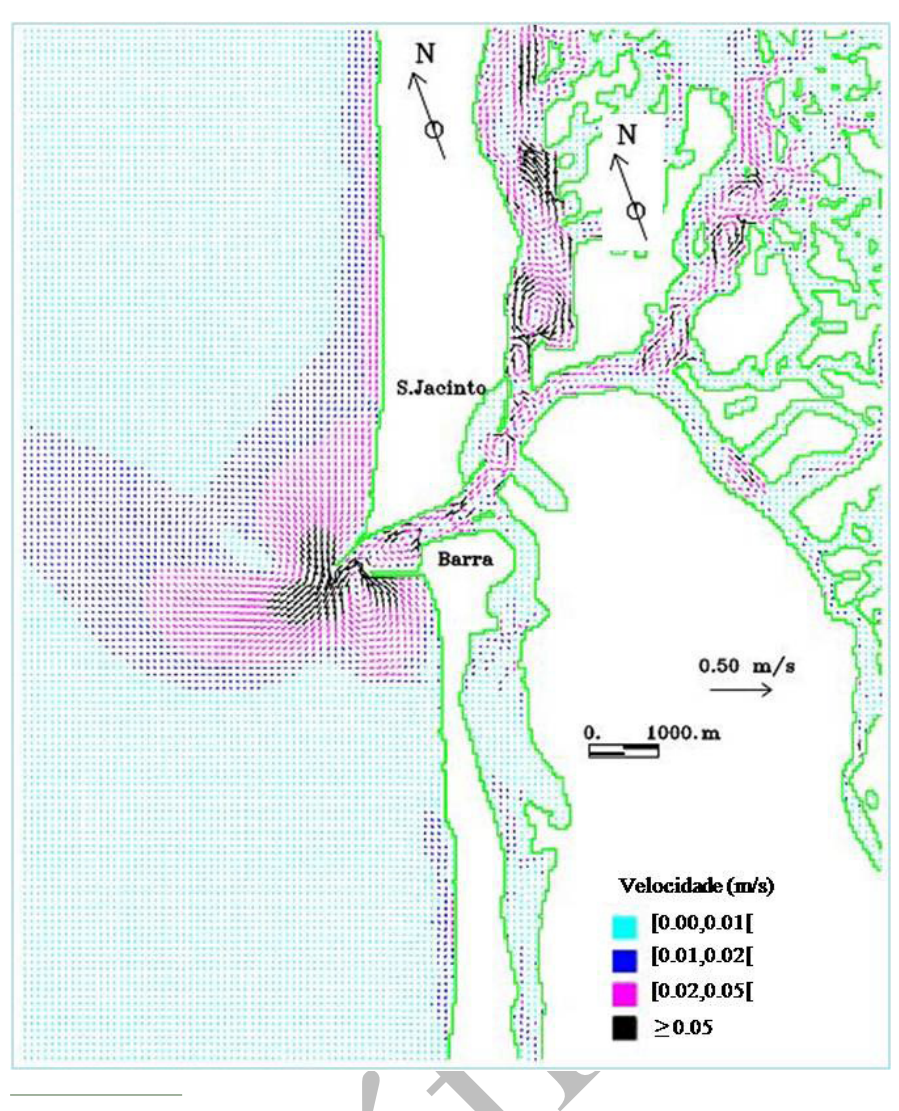

Figura 7. Velocidade residual da corrente (situação de referência). Figure 7. Residual current (baseline situation).

maré (modelo de correntes) de forma a obter as correntes combinadas de maré e ondas, responsáveis pelo transporte sedimentar. A resultante do transporte anual (figura 8) mostra que o transporte de sentido norte-sul, que ocorre ao longo do trecho situado a norte da barra de Aveiro, é essencialmente unidimensional. No entanto, na zona representada, até cerca de $6 \mathrm{~km}$ do molhe Norte, podem distinguir-se algumas zonas de maior intensidade desse transporte.

$\mathrm{Na}$ zona da barra e do banco da barra o transporte é marcadamente bidimensional, processando-se na circulação de um vórtice de sentido ciclónico. Esse vórtice abrange a embocadura, cruzando-a em dois sentidos: junto ao molhe Súl o transporte processa-se do exterior para o interior; junto ao molhe Norte é do interior para o exterior. Por seu lado, o progressivo aumento da intensidade do transporte ao longo do canal de navegação à medida que nos aproximamos da embocadura, cujo sentido é do interior para o exterior, configura uma tendência para erosão da zona terminal do canal, designadamente junto ao molhe Norte. Estas circulaçōes poderão dar origem a fenómenos cíclicos de assoreamento e erosão na zona da embocadura, tendendo a constituir um tampão contra a penetração de areias do mar no canal de navegação em direcção a montante na ria.

Estas tendências são coerentes com os resultados das comparações hidrográficas que foram apurados no ponto 2 e com a situação hidrográfica representada no levantamento da APA de Setembro de 2005. No entanto, ressalva-se que a periodicidade das alternâncias erosão-assoreamento junto às cabeças dos dois molhes nâo pode ser determinada com os elementos disponíveis. 


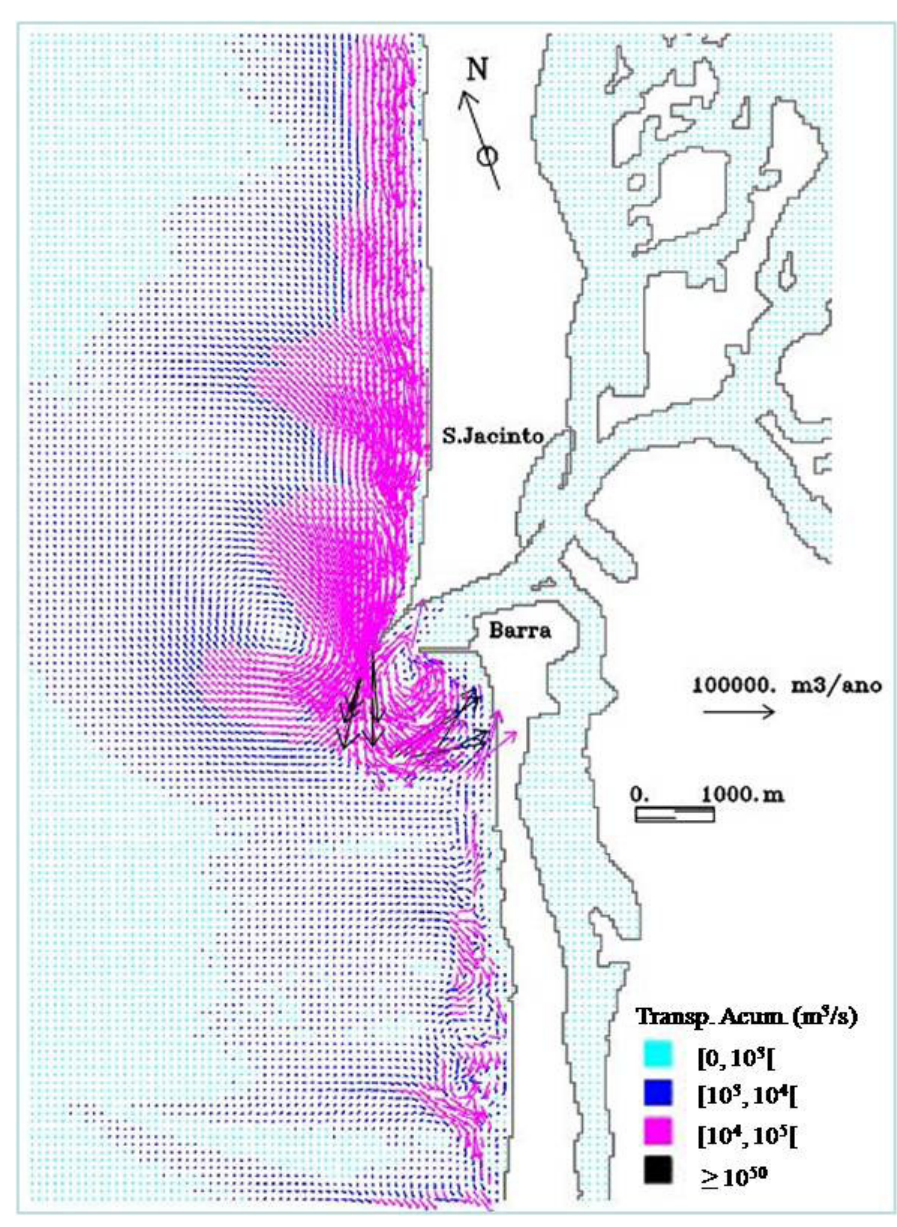

Figura 8. Resultante do transporte anual.

Figure 8. Annual sediment transport.

À existência daquele vórtice pode também ser atribuída, quer a acumulação aluvionar que se verifica no sub-trecho de costa de cerca de $3 \mathrm{~km}$ que se desenvolve para sul a partir da raiz do molhe Sul, quer a reduçâo do transporte de areia em direcção ao sul.

A seguir ao referido sub-trecho, em frente à Costa Noya, ocorre uma revessa do transporte, de sentido sul-norte. Esta revessa é a responsável pela formação em direcção ao norte das duas flechas representadas nas cartas náuticas naquele troço, que foram objecto de menção no âmbito da descrição da morfologia. Estes resultados tạmbém são confirmados pela própria geografia da evoluçáo do enchimento das praias da Costa Nova referida,no ponto 2. A existência dessa inversão do sentido geral da resultante do transporte anual ao longo da costa constitui um factor de decisão nas opçốes de deposição em frente à Costa Nová.

$\mathrm{Na}$ continuação do trecho de costa para sul da Costa Nova o transporte processa-se sob a forma de células em que a componente este-oeste assume por vezes significado em relação à componente norte-sul. Atribui-se este aspecto à não uniformidade hidrográfica do trecho, reflexo da não uniformidade da própria linha de costa. Ressalva-se, no entanto, que não se possui actualização hidrográfica junto à costa nesse trecho e que, na zona referida, os resultados deverão ser encarados com alguma prudência.

\subsubsection{Transporte em perfis transversais à costa}

Em complemento aos resultados atrás apresentados, mostram-se os gráficos da resultante do transporte anual ao longo de alguns perfis transversais à costa, assinalados na figura 9 , e a respectiva quantificação.

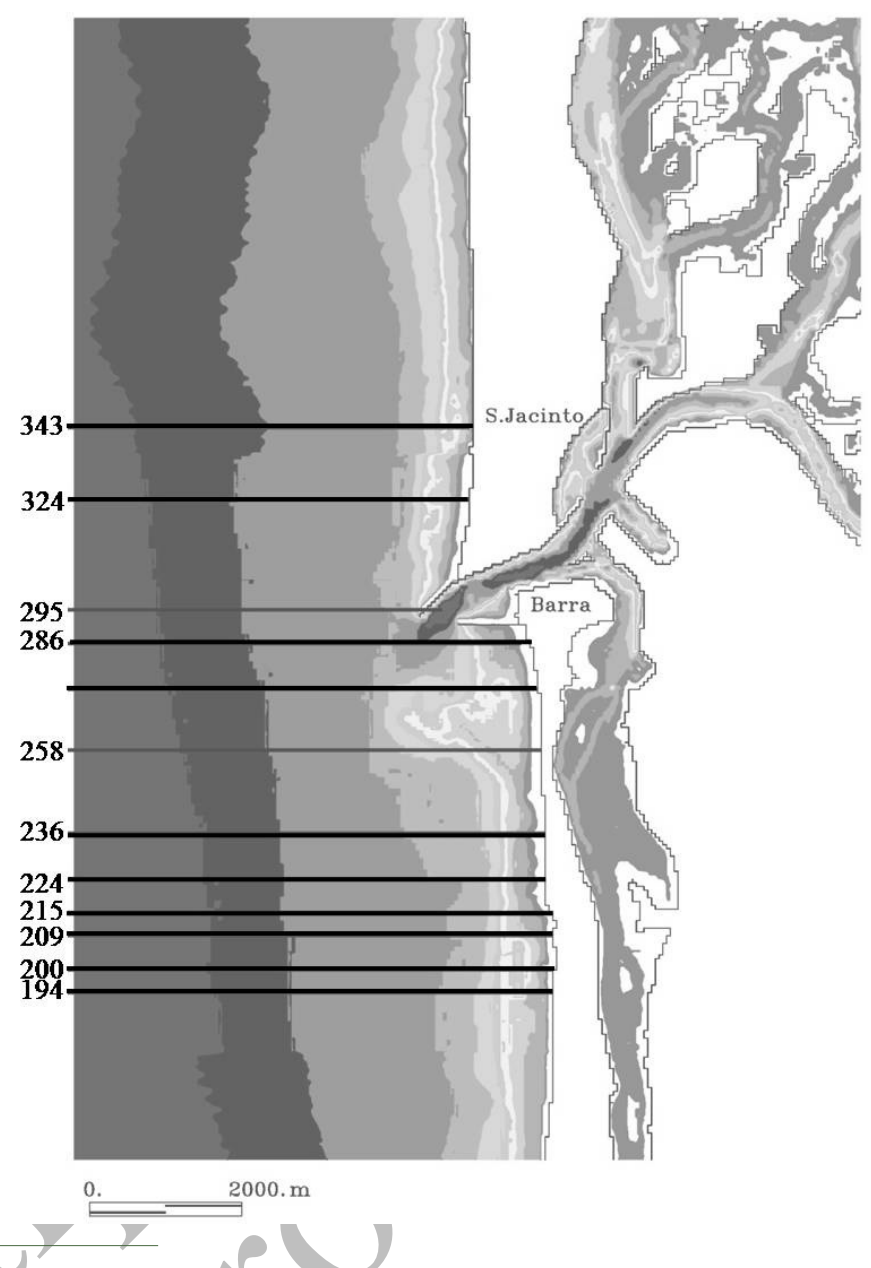

Figura 9. Localizaçáo dos perfis transversais à costa.

Figure 9. Localization of cross sections.

A análise do conjunto dos perfis registados na situação de referência mostra que, a norte da barra o transporte em direcção ao sul se processa entre a linha de costa e a isobatimétrica de $14 \mathrm{~m}$, com os picos de intensidade situados entre as isobatimétricas de $4 \mathrm{~m}$ e $8 \mathrm{~m}$ (figuras 10 e 11). O cálculo das componentes do transporte para sul, na situação de referência conduziu, respectivamente, nos perfis 343 e 324, aos valores $0,9 \times 10^{6} \mathrm{~m}^{3} /$ ano e $1,1 \times 10^{6} \mathrm{~m}^{3} /$ ano, aproximando-se a média de $1,0 \times 10^{6} \mathrm{~m}^{3} /$ ano. Este valor constitui o parâmetro de calibração do módulo do transporte sedimentar ao longo da costa, dado que é da ordem de grandeza do valor adoptado na literatura da especialidade, nomeadamente o proposto por Mota-Oliveira nos seus trabalhos (e.g. Mota-Oliveira, 1990).

Sobre o perfil 295 que intercepta a cabeça do molhe Norte o transporte adquire o valor aproximado de $0,6 \times 10^{6} \mathrm{~m}^{3} /$ ano. Por comparação com a média atrás apurada relativa ao 
Sittuaçăo de Referência

Solução de dragagem a norte do molhe Norte

PERFIL 343

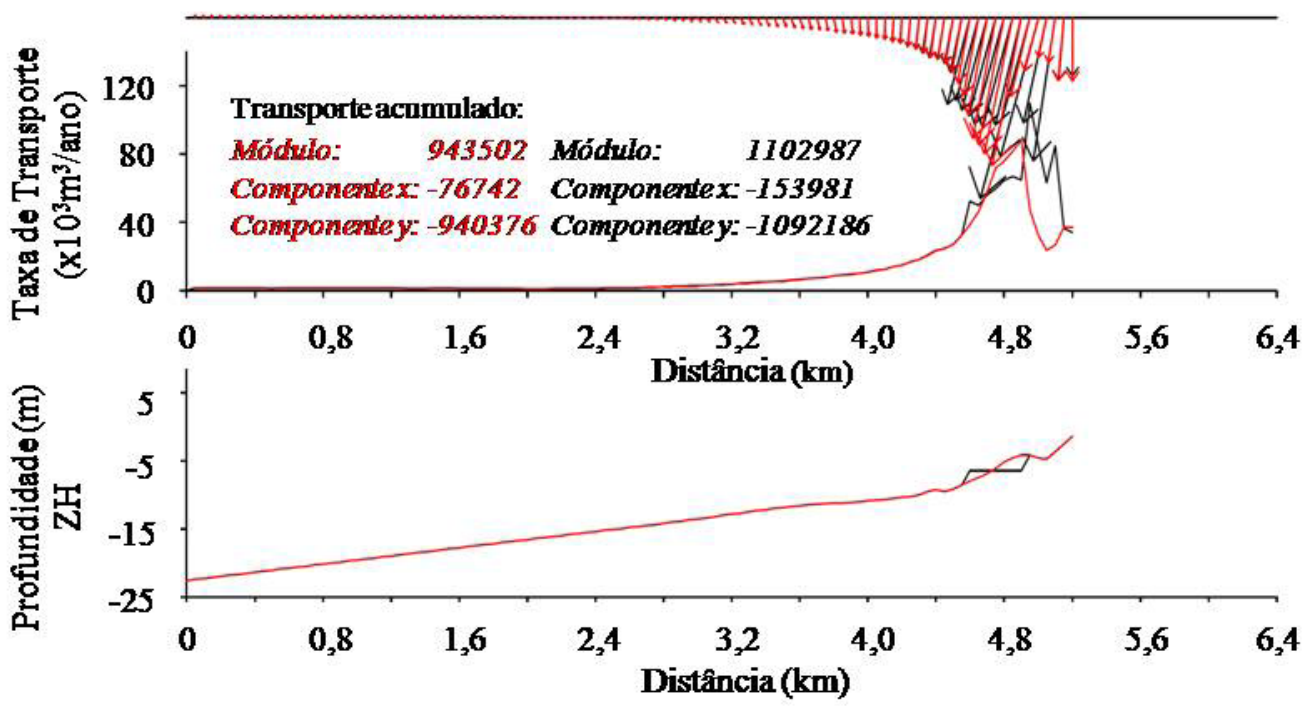

Figura 10. Perfil transversal de transporte anual de sedimentos. Situação de referência (343).

Figure 10. Cross section of annual sediment transport. Baseline situation (343).

Situaçāo de Referencia.

Solução de dragagem a norte do molhe Norte

PERFIL 324
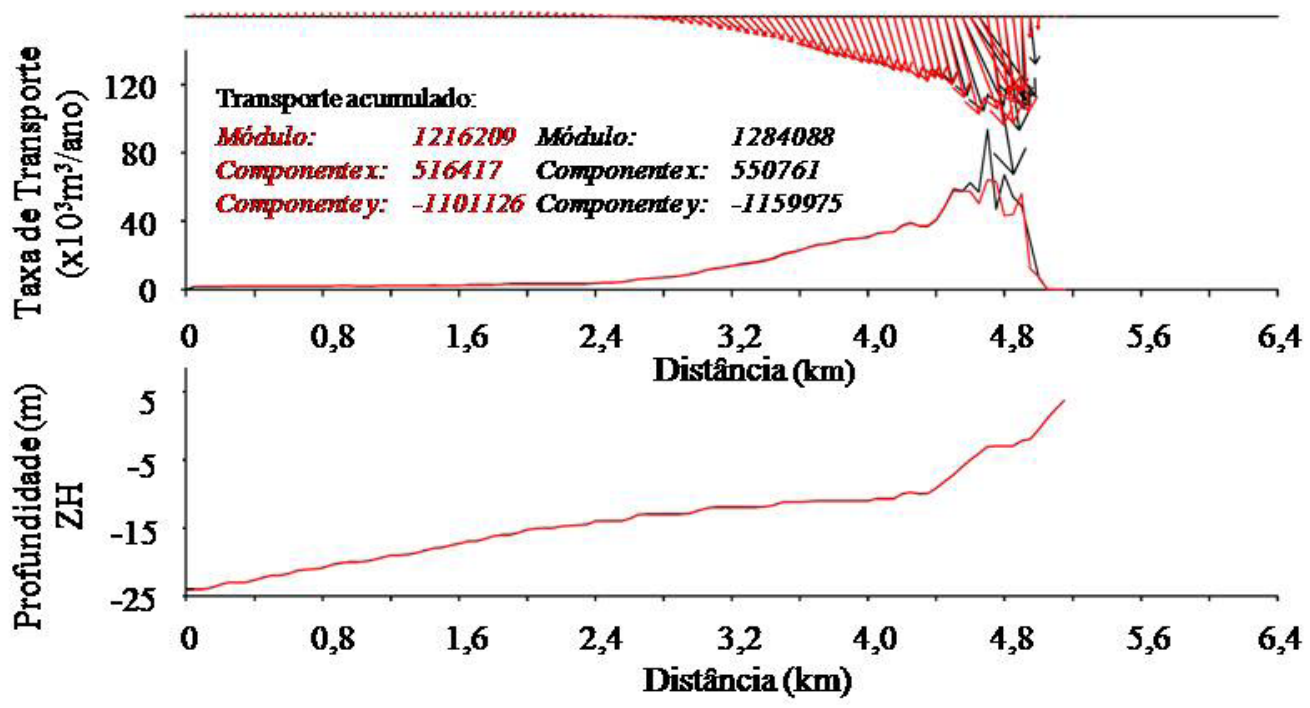

Figura 11. Perfil transversal de transporte anual de sedimentos. Situação de referência (324).

Figure 11. Cross section of annual sediment transport. Baseline situation (324).

trecho adjacente a norte, pode deduzir-se que os resultados revelaram a existência de capacidade de acumulação por parte do molhe Norte.

Sobre o banco da barra, no perfil 274 (figura 12), distinguem-se duas componentes principais do transporte sedimentar: uma componente sul-sueste, responsável pelo encaminhamento de areias em direcção ao trecho a sul; e uma componente les-nordeste, responsável pela acumulação de areia no sub-trecho de costa entre o molhe Sul e a Costa Nova.
No trecho sul adjacente ao banco da barra o transporte junto à costa sofre uma diminuição comparativamente aos valores que se têm vindo a analisar. De facto, segundo as direcçóes, aproximadamente, perpendicular e ao longo da costa, os valores na situação de referência, são, respectivamente, iguais a $-49464 \mathrm{~m}^{3}$ /ano (sentido offshore) e $3885 \mathrm{~m}^{3} /$ ano (sentido para norte), no perfil 200 (figura 14), e $12770 \mathrm{~m}^{3}$ /ano (sentido onshore) e $18213 \mathrm{~m}^{3} /$ ano (sentido para norte), no perfil 194 (figura 15). 


\subsection{Situaçáo de projecto}

\subsubsection{Dragagem a norte do molhe Norte}

Os resultados da simulação do transporte sedimentar na presença de uma dragagem de $1,0 \times 10^{6} \mathrm{~m}^{3}$ na zona a norte do molhe Norte mostram que ocorre intensificação do transporte entre a zona dragada e a linha de costa no troço dragado, relativamente à situaçáo da referência, respectivamente, segundo as direcçóes, aproximadamente, perpendicular e ao longo da costa, com os valores $-0,15 \times 10^{6} \mathrm{~m}^{3} /$ ano e $-1,1 \times 10^{6} \mathrm{~m}^{3} /$ ano (perfil 343, conforme a figura 10) e $-0,5 \times 10^{6} \mathrm{~m}^{3} /$ ano e $-1,2 \times 10^{6} \mathrm{~m}^{3} /$ ano (perfil 324, conforme a figura 11). Este processo é uma consequência do aumento da energia das ondas junto à costa proporcionado pela dragagem, que induz um aumento das taxas de transporte sobre o perfil. A intensificação do transporte nas proximidades da linha de costa tenderá a originar temporariamente o seu recuo nesse troço. Estima-se que o referido recuo configure uma área de 0,5 ha, sobre a extensão de $1500 \mathrm{~m}$ de costa e que atinja a profundidade máxima de cerca de $10 \mathrm{~m}$. Em seguida, a linha de costa tenderá a recompor-se.

No sector de costa a sul do troço dragado ocorrerão, temporariamente, duas tendências opostas: receberá o excesso de areias associado ao aumento do transporte sobre a linha de costa registado no troço adjacente a norte e terá défice de areia entre as isobatimétricas de $3 \mathrm{~m}$ e $7 \mathrm{~m}$, visto que a zona dragada poderá funcionar como sumidouro nessas profundidades. As duas tendências tenderão a compensar-se, de forma que o troço não deverá sofrer alterações morfológicas significativas. Estas estimativas assentam na comparação das taxas de transporte registadas sobre os perfis transversais dos troços em análise, e da aplicação da equação da continuidade aplicada ao balanço de areia na zona costeira:

$$
\frac{\partial Q s}{\partial x}+H \frac{\partial y}{\partial t}=0
$$

Onde: $Q$ - o volume de areia transportada $\left(\mathrm{m}^{3}\right) ; y$ - largura do perfil de praia activo (m); $H$ - altura do perfil de praia activo (m); $x$ - coordenada longitudinal (segundo a direcçáo da linha de costa); $t$ - tempo.

As estimativas atrás apresentadas tiveram por base a especificação de $10 \mathrm{~m}$ para a altura do perfil de praia activo. Os valores dos transportes foram calculados para os referidos perfis transversais na situação de referência e na situação de projecto.

\subsubsection{Dragagem sobre o banco da barra}

Os resultados da simulação da dragagem de $1,0 \times 10^{6} \mathrm{~m}^{3}$ na zona a sul da barra, sobre o banco da barra, mostraram que o padrão do transporte da areia segundo uma circulaçáo de sentido directo se mantém como se pode verificar no perfil 274 , apresentado na figura 12 . No entanto, o seu centro desloca-se em direcção à costa como resultado do decréscimo da dissipação da energia da ondulaçáo sóbre o sector dragado do banco.

As componentes do transporte para sul tendem a aumentar no sector norte do banco e a diminuir no sector sul, indicando que o banco tenderá a reconstituir-se. $\mathrm{O}$ processo de reconstituiçấo tende a ser mais lento do que no

Sïtuaçäo de Referência

Solução de dragagem sobre o banco da Barra
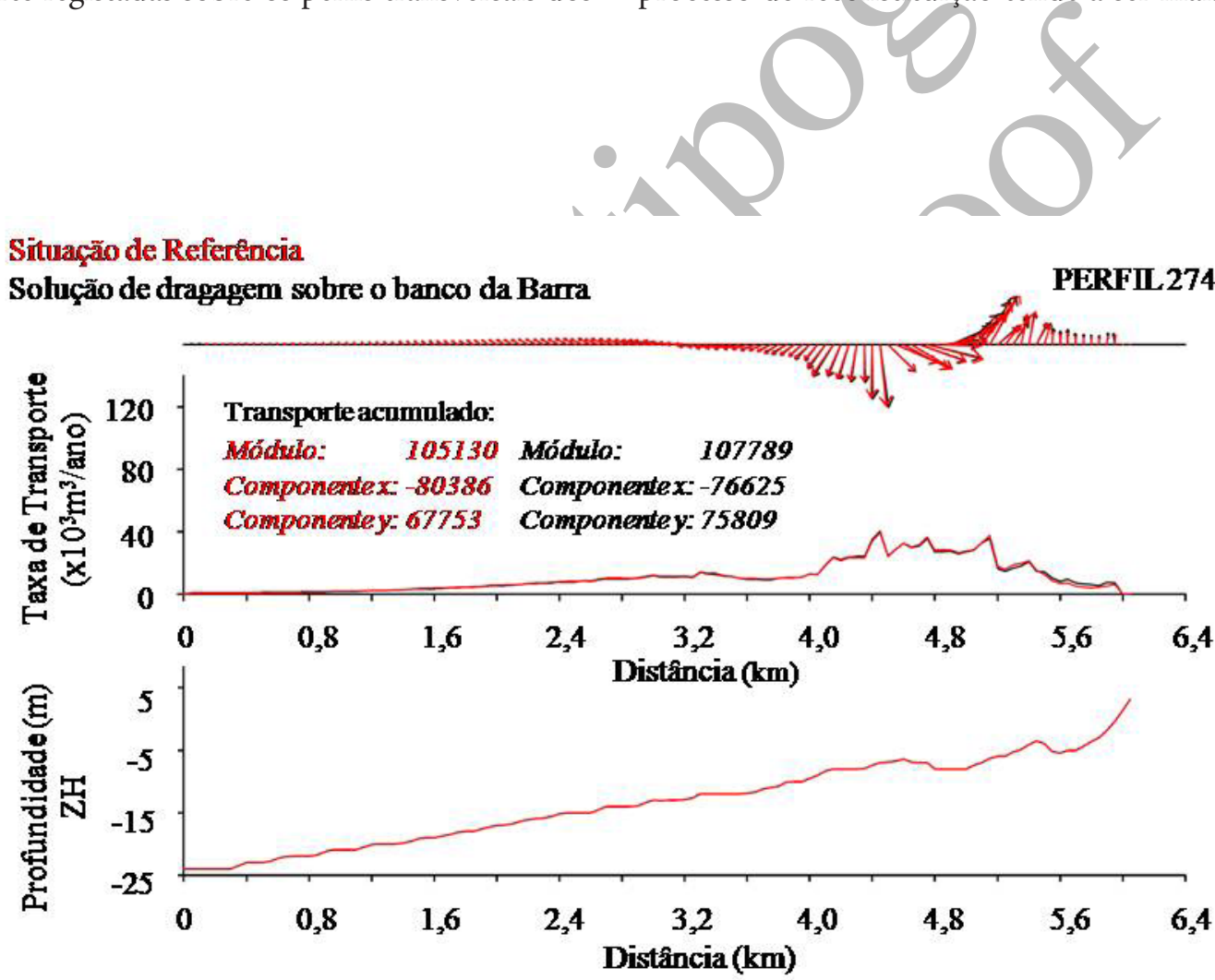

Figura 12. Perfil transversal de transporte anual de sedimentos. Dragagem no banco da barra (274). Figure 12. Cross section of annual sediment transport. Dredging at the bank of the bar scenario (274) 
passado (até 1988) enquanto se mantiver a diminuição do transporte sobre o perfil da cabeça do molhe Norte. Como consequência, não é de esperar alteração significativa da passagem de areia para sul.

Refere-se o facto de o banco da barra constituir uma peça fundamental do sistema morfo-dinâmico da região, podendo constituir simultaneamente um obstáculo ao encaminhamento das areias em direcção ao sul e um elemento de protecção da costa entre os núcleos urbanos da Barra e da Costa Nova.

\subsubsection{Dragagem na zona da barra}

Os resultados da simulaçáo da dragagem de $1,0 \times 10^{6} \mathrm{~m}^{3}$ na zona da barra, segundo as especificações já referidas, mostram que se intensifica muito significativamente a taxa de transporte na vizinhança da cabeça do molhe Norte, particularmente junto a essa extremidade. Esta intensificação, com valores, que no perfil 295 , são da ordem de $1,47 \times 10^{6} \mathrm{~m}^{3}$ (segundo a direcção norte-sul), fica a dever-se à maior exposição que esse local passa a ter relativamente ao mar de oeste e de sudoeste, por efeito do aumento da profundidade na zona que lhe é fronteira. Refira-se que o perfil 295 não intercepta a área de dragagem.

Pelo contrário, regista-se a diminuição da taxa de transporte sobre a zona de dragagem, como se pode ver no perfil 286 (figura 13) como esperado, por efeito do aumento das profundidades. A combinação destas acçôes converge para criar uma forte tendência de assoreamento da zona dragada que, deste modo, necessitará de frequentes dragagens de manutenção.

\subsubsection{Deposiçáo no mar a sul do $5^{\circ}$ esporáo da Costa Nova}

Os resultados da simulaçáo da deposição de $0,5 \times 10^{6} \mathrm{~m}^{3}$ no mar, imediatamente a sul do quinto esporão da Costa Nova, numa extensão de $1000 \mathrm{~m}$ ao longo da costa entre as isobatimétricas de $2 \mathrm{~m}$ e $5 \mathrm{~m}$, mostram que se obtém a diminuição da taxa de transporte sobre a linha de costa, cf. Perfis 200 (Figura 14) e 194 (figura 15). O avanço da linha de costa associado a este efeito poderá ser considerado desprezável.

No sector adjacente a sul poderá ocorrer uma tendência inicial para o recuo da linha de costa que será invertida à medida que as areias depositadas forem mobilizadas para sul. Esse recuo deverá ser inferior a cerca de $10 \mathrm{~m}$. A componente sul da taxa de transporte também aumenta, embora em proporção inferior à da componente transversal. Este padrão de transporte indica uma tendência para a permanência das areias na zona por um prazo alargado, que poderá ser da ordem de grandeza de anos.

Como anteriormente, estas estimativas assentaram nos resultados calculados para os perfis transversais do transporte sedimentar na situação de referência e na situaçâo de projecto e na aplicação da equação da continuidade ao balanço de areia no troço.

\subsubsection{Deposiçöes no mar entre o $3^{\circ}$ e $4^{\circ}$ esporöes da Costa Nova}

Prevê-se a deposição a ser feita num sub-sector junto à costa onde é predominante a componente do transporte em direcção a terra e onde ainda se verifica a já assinalada revessa do transporte em direcção ao norte, isto é, da inversão para norte da resultante do transporte anual, como pode ver-se nas figuras 16 e 17 correspondentes aos perfis 236 e 224 .

Situação de Referência

Solução de dragagem a norte do molhe Norte
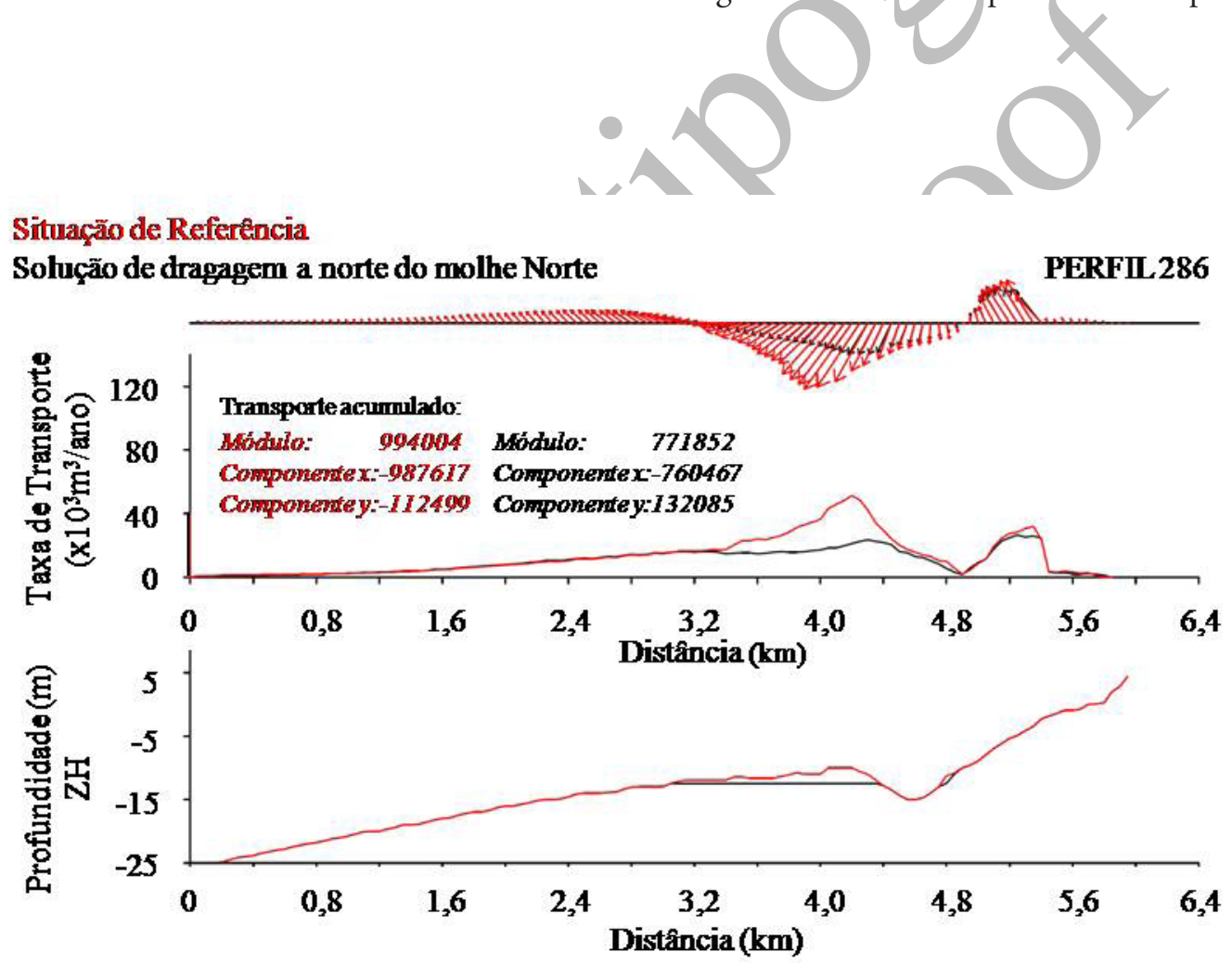

Figura 13. Perfil transversal de transporte anual de sedimentos. Dragagem da zona da Barra (286).

Figure 13. Cross section of annual sediment transport. Dredging at the bar scenario (286) 
Sïtuaçäo de Referência

Deposição a sul do $5^{\circ}$ esporão

PERFIL 200

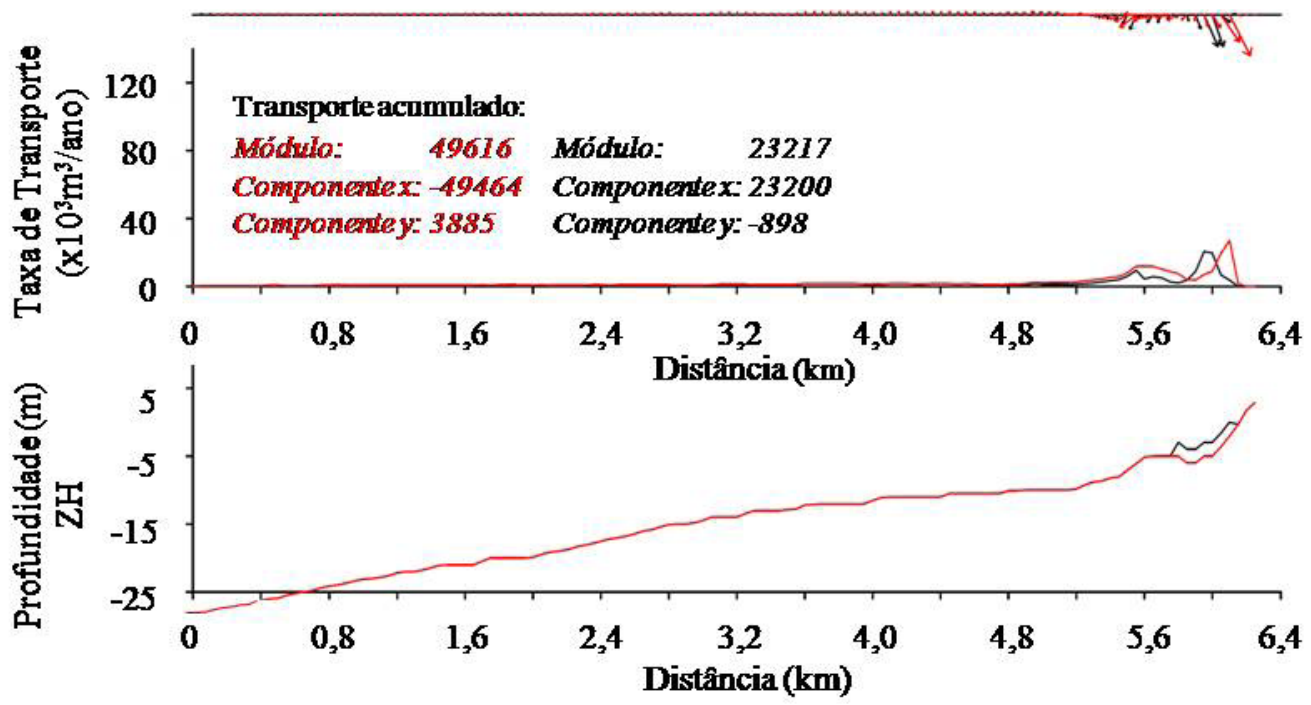

Figura 14. Perfil transversal de transporte anual de sedimentos. Deposição a sul do $5^{\circ}$ esporão da Costa Nova (200). Figura 14. Cross section of annual sediment transport. Deposition south of the fifth Costa Nova coastal groin (286).

Sïtuação de Referência.

Deposição a sul do $5^{\circ}$ esporão

PERFIL 194
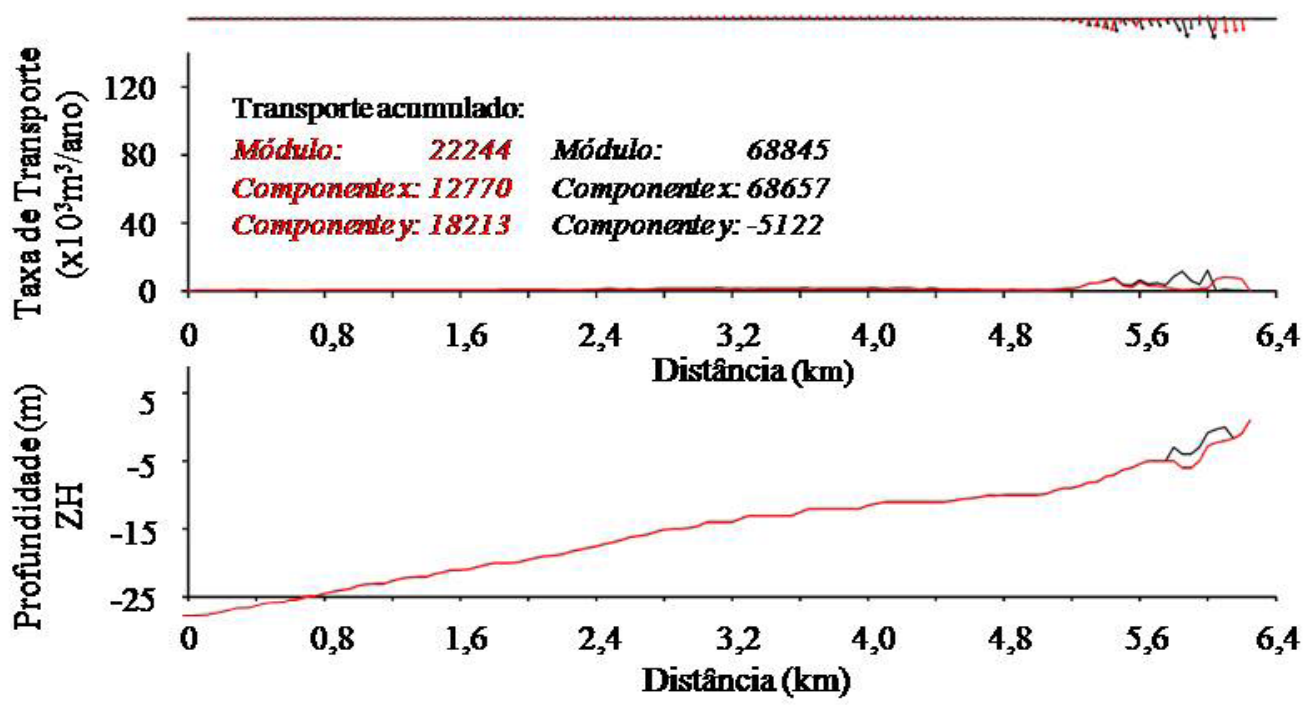

Figura 15. Perfil transversal de transporte anual de sedimentos. Deposição a sul do $5^{\circ}$ esporão da Costa Nova (perfil 194).

Figure 15. Cross section of annual sediment transport. Deposition south of the fifth Costa Nova coastal groin (194). 
Sittuaçäo de Referência

Deposição entre o $3^{\circ}$ e $04^{\circ}$ esporão da Costa Nova

PERFIL 236

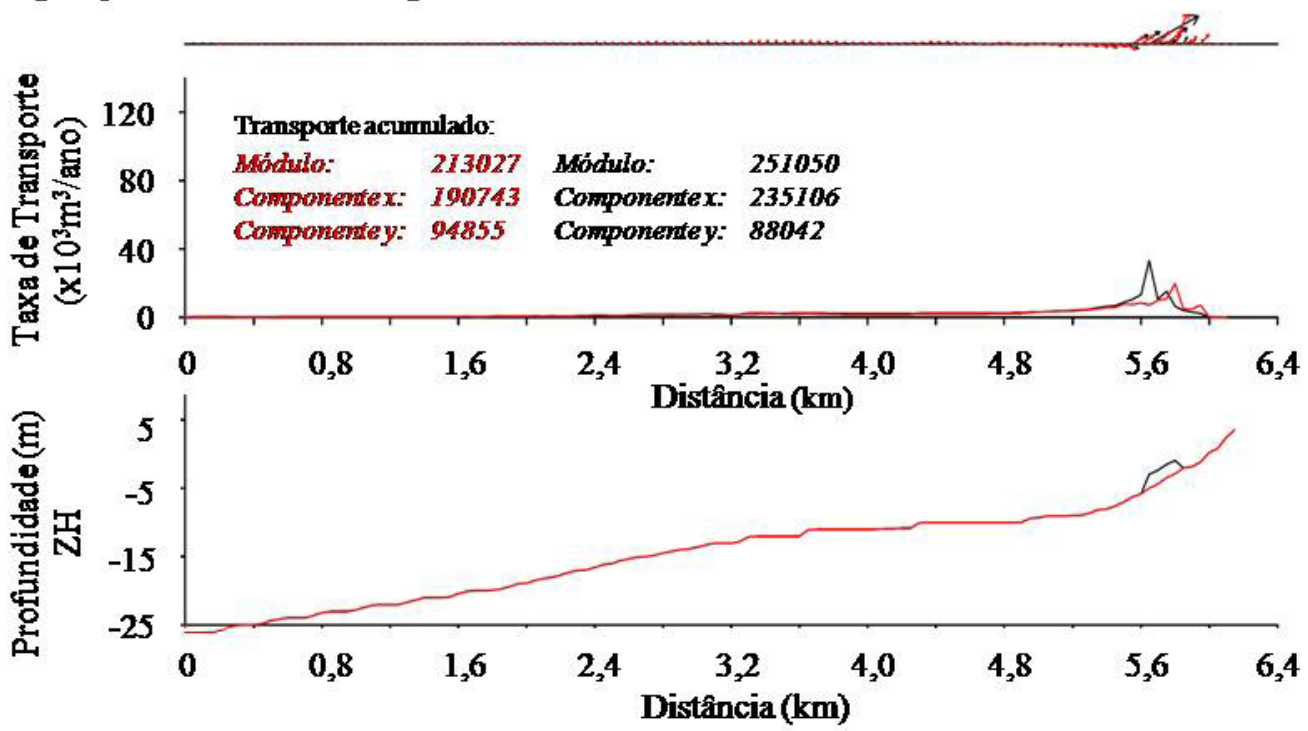

Figura 16. Perfil transversal de transporte anual de sedimentos. Deposição entre o $3^{\circ}$ e o $4^{\circ}$ esporáo da Costa Nova (236).

Figure 16. Cross section of annual sediment transport. Deposition between the third and forth Costa Nova coastal groins (236).

Sïtuaçäo de Referência

Deposição entre o $3^{\circ}$ e $04^{\circ}$ esporão da Costa Nova

PERFIL 224

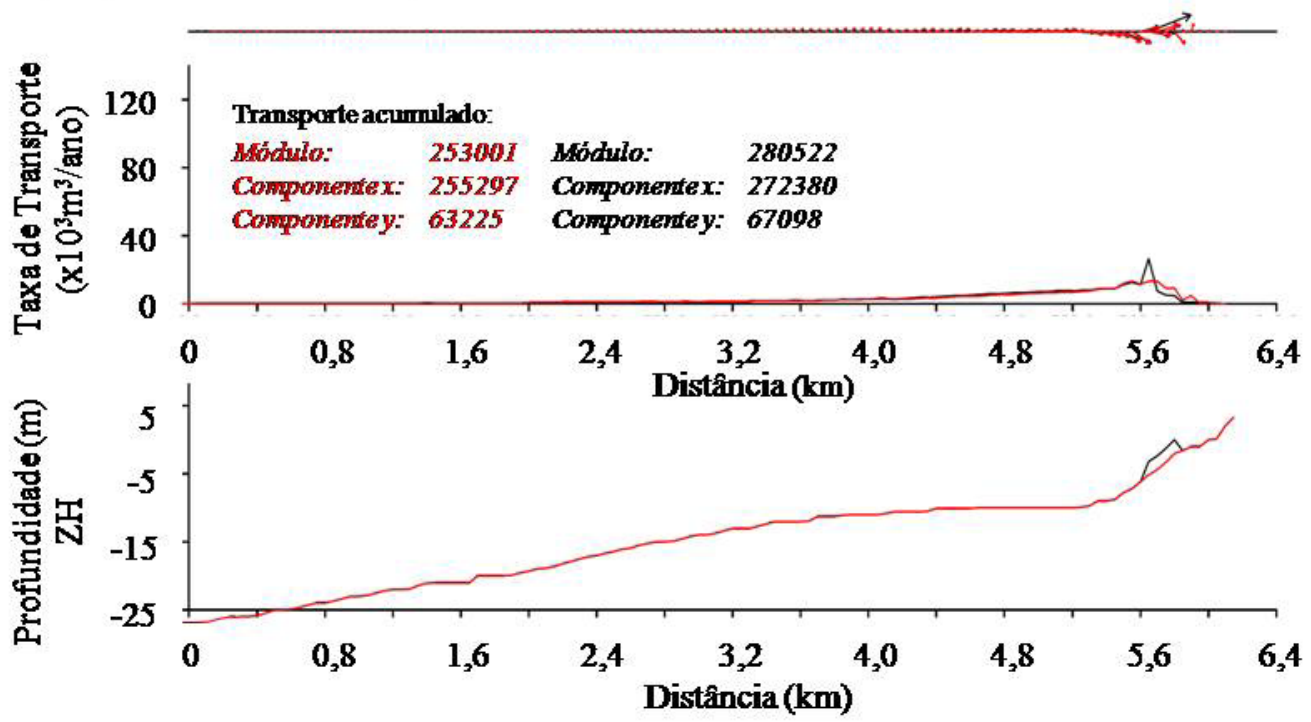

Figura 17. Perfil transversál de transporte anuál de sedimentos. Deposição entre o $3^{\circ}$ e o $4^{\circ}$ esporão da Costa Nova (perfil 224).

Figure 17. Cross section of annual sediment transport. Deposition between the third and forth Costa Nova coastal groins (224). 
Deste modo, é elevada a probabilidade de as areias depositadas ficarem retidas no sector por um período alargado. A deposição de $0,5 \times 10^{6} \mathrm{~m}^{3}$ de areia no mar nas profundidades especificadas previsivelmente induzirá intensificação do transporte sobre a zona de deposição, ocorrendo simultaneamente a sua inflexão em direç̧ão à costa. A componente do transporte em direcção à costa suporta uma tendência para acumulaçâo sedimentar sobre a linha de costa estimada em cerca de $50000 \mathrm{~m}^{3} / \mathrm{ano}$.

Por outro lado, prevê-se uma diminuição do transporte sobre a linha de costa, como resultado da intercepção das ondas por parte do depósito fronteiro, o que reforçará a tendência para a estabilizaçáo da linha de costa.

\subsubsection{Deposiçóes no mar entre o $4^{\circ}$ e o $5^{\circ}$ esporóes da Costa Nova}

Este sub-sector situa-se já fora do alcance da inversão para norte da resultante do transporte anual que se regista no sub-sector anterior. Como já assinalado anteriormente, esta poderá ser a causa da não recriação da praia nesse local. Pela mesma razáo, os efeitos associados à deposição de $0,5 \times 10^{6} \mathrm{~m}^{3}$ de areia no mar diferem dos registados para o sub-sector a norte, sendo de esperar (figuras 18 e 19, correspondentes, respectivamente aos perfis 215 e 209), que ocorra a diminuição da taxa de transporte junto à linha de costa, o que induzirá tendência para o seu avanço.

Pelo facto de a resultante do transporte anual junto à costa ser já em direcção a sul, embora de reduzida intensidade, esse avanço será potenciado pela presença do $5^{\circ}$ esporão, cuja extensão se encontra presentemente praticamente toda no mar. Um eventual prolongamento da referida estrutura poderia aumentar a eficácia da retenção.

Parte das areias depositadas deveráo ultrapassar o $5^{\circ}$ esporão em direcção ao sul, podendo vir a formar uma praia de difracção junto à raiz desse esporão. $\mathrm{A}$ inversão desta tendência acompanhará a progressiva deslocação para sul das areias depositadas.

\section{CRITÉRIOS DE COMPARAÇÃO DAS SOLUÇÓES}

Após a interpretação dos resultados obtidos por modelação matemática a fase seguinte do estudo comportou a aplicação de um método multi-critério de análise comparativa das soluções de dragagem e de deposiçáo estudadas, na qual foram considerados critérios técnicos, económicos e ambientais, por seu turno divididos nos sub-critérios seguintes:

(1) Critérios técnicos: objectividade (melhoria das condiçóes de acesso marítimo ao porto de Aveiro e o contributo directo para a protecçẫo do cordão dunar contra a erosão); urgência (brevidade com que cada solução pode ser levada a concurso e executada); fundamentação (grau de conhecimento; quantificação dos processos da dinâmica costeira envolvidos; previsão dos seus efeitos); viabilidade técnica e oportunidade (capacidade, exigência e disponibilidade dos meios e equipamentos a empregar nas operaçóes de dragagem e de deposiçẫo dos dragados; clima de agitação marítima ao longo do ano, para a dragagem e a deposição); adaptabilidade (condiçôes topográficas e hidrográficas actuais das zonas de empréstimo e de deposição; operacionalidade (condicionantes associadas à operaçẫo contínua do porto de Aveiro).

(2) Critérios éconómicos englobando: custo estimado de cada soluçấo (os custos fixos de mobilização e os custos

\section{Sïtuaçäo de Referência}

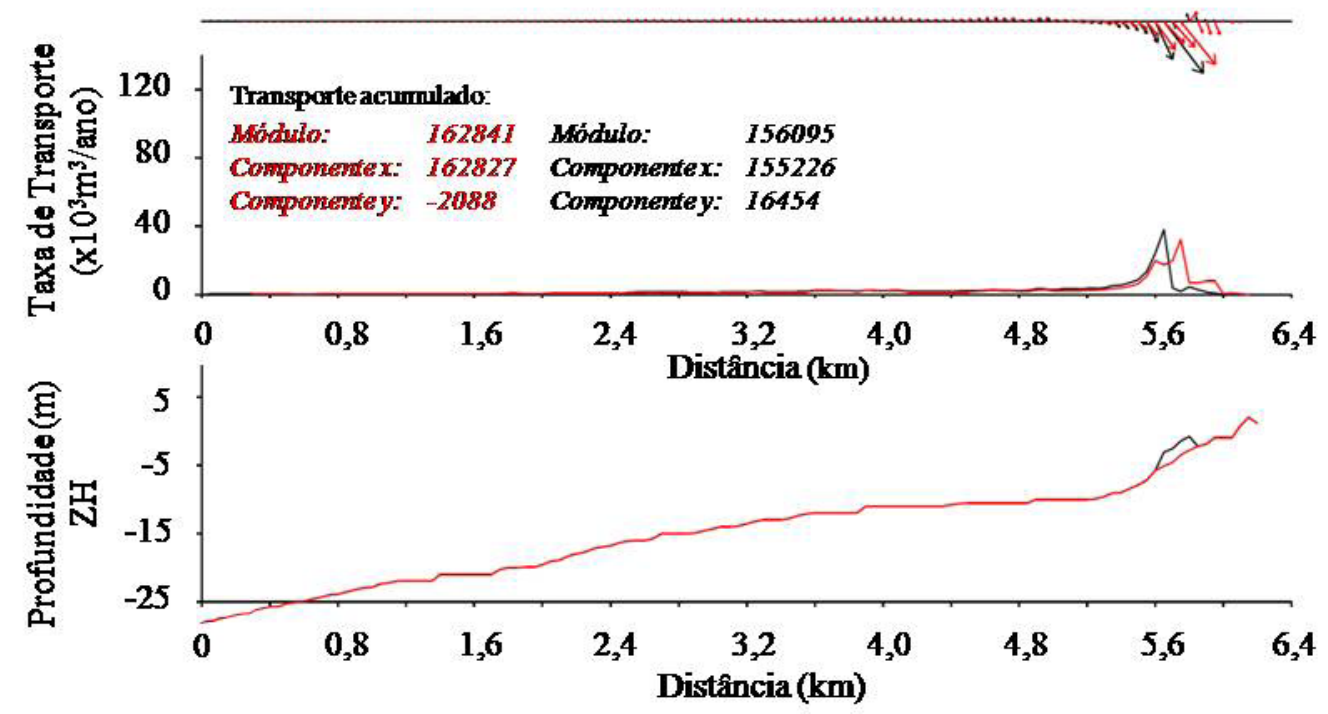

Figura 18. Perfil transversal de transporte anual de sedimentos. Deposição entre o $4^{\circ}$ e o $5^{\circ}$ esporão da Costa Nova (perfil 215).

Figure 18. Cross section of annual sediment transport. Deposition between the forth and the fifth Costa Nova coastal groins (215). 
Sïtuaçăo de Referência

Deposição entre $04^{\circ}$ e o $5^{\circ}$ esporão da Costa Nova

PERFIL 209

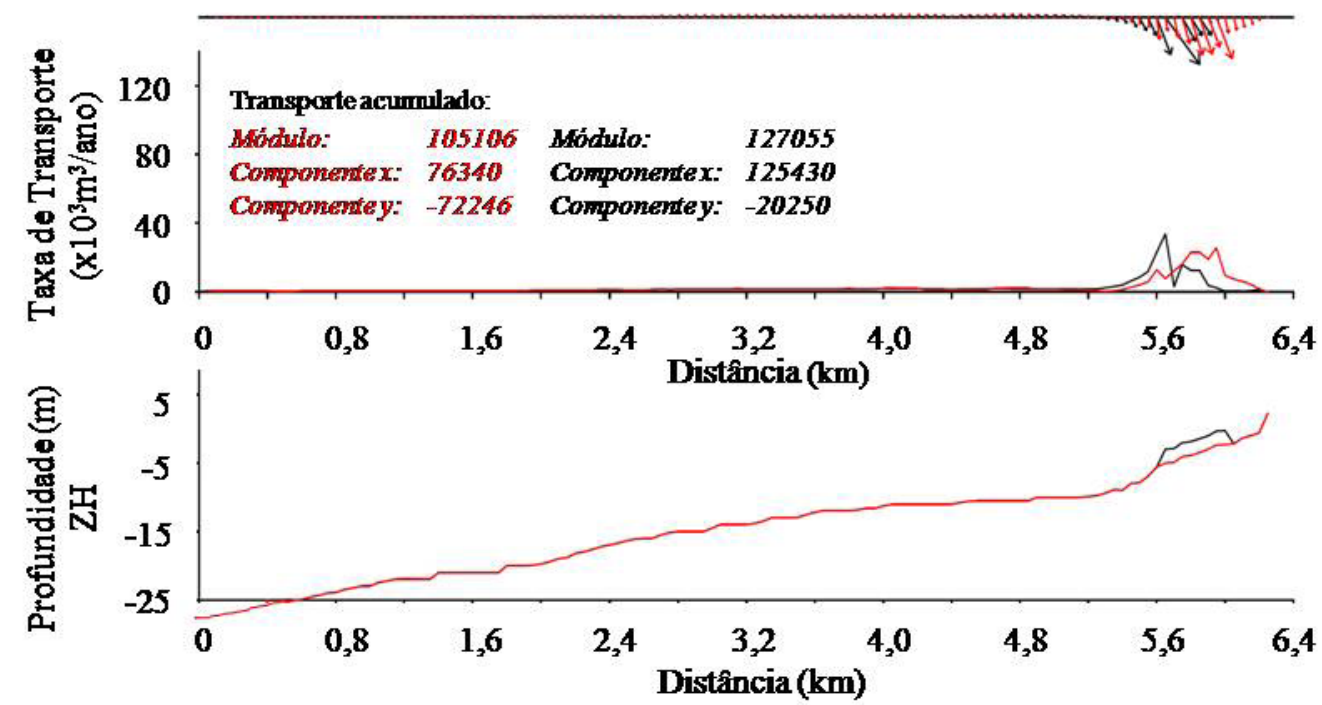

Figura 19. Perfil transversal de transporte anual de sedimentos. Deposição entre o $4^{\circ}$ e o $5^{\circ}$ esporão da Costa Nova (perfil 209).

Figure 19. Cross section of annual sediment transport. Deposition between the forth and the fifth Costa Nova coastal groins (209)

unitários de operação); risco económico (eficiência de cada solução); benefícios (maximização do impacte positivo da utilizaçáo das areias no combate à erosão costeira).

(3) Critérios ambientais: impactes sobre os ecossistemas terrestres (evitar a interferência com a nidificação da avifauna no cordão dunar); impactes sobre os habitats de bivalves (evitar ou reduzir a sua destruição); impactes sobre a utilização das praias (evitar ou reduzir a interferência com a época balnear); interferência com a navegação (manobra dos navios e das dragas); impacte sócio-económico (desenvolvimento do porto de Aveiro); viabilização (relativa ao reforço periódico do cordão dunar).

No que respeita os critérios ambientais é de salientar que todas as zonas de dragagem e de deposição consideradas se encontram inseridas em Rede Natura 2000 que constitui um instrumento da política da Uniâo Europeia relativa à conservação da Natureza e da diversidade biológica (Resolução do Conselho de Ministros n.o 115-A/2008, da legislação portuguesa). Ao abrigo da classificaçẫo referida, a zona em estudo está então integrada na Zona de Protecção Especial da Ria de Aveiro, criada pelo Decreto-Lei no 384-B/99 de 23 de Setembro, também da legislação portuguesa.

Não foram estabelecidas diferenças entre os locais em termos de ordenamento, mas apenas em termos de habitats. De entre estes, foi considerado que apenas os de bivalves, no mar, e os da avifauna, em terra, seriam de reter para efeitos de análise comparativa. Os impactes positivos sobre o desenvolvimento do porto de Aveiro, bem como os impactes, igualmente positivos, da viabilização de repetiçóes periódicas de acçóes de reforço do cordão dunar foram também retidos na análise comparativa das soluçóes.

Cada um dos sub-critérios mencionados anteriormente foi aplicado na comparação dos locais de dragagem e de deposição e dos métodos tecnológicos de intervenção. As tabelas 4 e 5 apresentam os resultados do estudo multi-critério, que considerou a atribuição de igual ponderação aos sub-critérios. Este facto contribuiu decisivamente para a escolha da solução final.

A aplicação do método multi-critério referido de análise comparativa das soluçóes de dragagem e de deposição estudadas conduziu ao seguinte ordenamento relativo das três soluçóes mais pontuadas:

1) Dragagem na barra com deposiçóes nos locais A1 e A2, integralmente no mar entre os terceiro e quinto esporóes da Costa Nova; 2) Dragagem sobre o banco da barra igualmente com deposiçóes nos locais A1 e A2, integralmente no mar, entre os terceiro e quinto esporóes da Costa Nova; 3) Dragagem na barra, com deposiçóes B1 e B2, respectivamente no mar e em terra, entre os quarto e quinto esporóes da Costa Nova.

Comentam-se seguidamente as vantagens e os inconvenientes relativos de cada uma das três soluçóes atrás indicadas, no intuito de aprofundar a compreensáo do ordenamento obtido.

1) Dragagem na barra com deposição nos locais A1 e A2

A solução de dragagem na barra deve o primeiro lugar à pontuação obtida simultaneamente nos critérios económico e ambiental, sobretudo neste último. A dragagem na barra satisfaz plenamente nos seguintes sub-critérios: objectividade e de adaptabilidade; benefícios; e em todos os critérios ambientais excepto no de interferência com a navegação. Por outro lado esta solução é penalizada nos sub-critérios: fundamentação técnica e interferência com a operacionalidade da barra e risco económico.

As deposiçóes nos locais A1 e A2 devem também o primeiro lugar à pontuação obtida nos três critérios, com destaque para 
o critério ambiental. A deposição integralmente no mar satisfaz plenamente nos sub-critérios: urgência, viabilidade técnica e adaptabilidade; custo, eficiência e economias de escala; e minimiza os impactes sobre a avifauna e sobre a utilização balnear das praias. Por outro lado, esta solução de deposição não é penalizada em nenhum dos sub-critérios.

2) Dragagem sobre o banco da barra com deposições nos locais A1 e A2

Esta solução difere da anterior pela mudança do local de dragagem. A dragagem no banco obtém melhor pontuação no critério técnico. Relativamente aos sub-critérios a dragagem no banco pretere a dragagem na barra nos seguintes: urgência, viabilidade técnica e operacionalidade; custo; interferência com a navegação. Neste último sub-critério considerou-se que diferença entre as soluçôes é a mínima, visto que a prática da barra pela navegaçáo está sob o controle total do Departamento de Pilotagem do Porto de Aveiro.

3) Dragagem na barra, com deposiçóes nos locais B1 e B2

Esta solução difere da primeira soluçáo pela mudança dos locais de deposiçâo. Os locais B1 e B2 preterem os locais C1 e C2 nos seguintes sub-critérios: objectividade e grau de fundamentação; benefícios; impactes sobre os bivalves.

\section{CONCLUSÁO}

Da análise comparativa efectuada resultou que a solução de dragagem da barra, com deposição no mar entre os terceiro e quinto esporốes do campo de esporôes da Costa Nova foi a que melhor satisfez os critérios de análise adoptados, técnicos, ambientais e económicos e, por esta razão foi a preconizada. Essa solução pressupôs que se considerassem dragagens de manutenção anuais ou plurianuais, cujos dragados terão como destino a protecção da zona costeira a sul, com o mesmo enquadramento. Neste contexto, a solução preconizada equivale a uma permanente transposição artificial da barra de Aveiro, intervenção há muito reclamada em termos ambientais.

As soluções escolhidas foram implementadas pelas instituiçôes com jurisdição na área, depois de 2008. Numa fase final o estudo recomendou o desenvolvimento de um programa de monitorização regular a ter lugar após a implementação do projecto, de forma a tornar possível uma avaliaçáo objectiva da evolução sedimentar nas áreas de dragadas e de depósito.

$\mathrm{O}$ estudo efectuado constitui uma contribuição para a gestão costeira efectuada de forma integrada na zona, uma vez que contribuiu decisivamente para a definição e implementação de uma solução para o problema na área costeira em análise.

Tabela 4. Principais critérios utilizados na escolha de soluçôes de dragagem.

Table 4. Main criteria used to choose the final dredging solution.

\begin{tabular}{|c|c|c|c|}
\hline \multirow{12}{*}{ 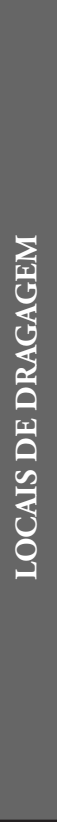 } & \multirow{5}{*}{$\begin{array}{c}\text { NORTE DO } \\
\text { MOLHE } \\
\text { NORTE }\end{array}$} & \multirow{2}{*}{ Vantagens } & Retarda o processo de assoreamento da barrâ \\
\hline & & & Constitui o esquema mais próximo de uma transposição artificial de areia \\
\hline & & \multirow{3}{*}{ Desvantagens } & Não resolve, no curto prazo, o desassoreamento da barra \\
\hline & & & $\begin{array}{l}\text { Constitui uma soluçáo de dragagem mais afastada do local de depósito o que implica } \\
\text { maiores custos de execução }\end{array}$ \\
\hline & & & Execução mais difícil, dado que as dragas terão que operar mais próximo de terra \\
\hline & \multirow{4}{*}{ BARRA } & \multirow{2}{*}{ Vantagens } & Resolve as necessidades imediatas de dragagem \\
\hline & & & Operação de fácil execução \\
\hline & & \multirow{2}{*}{ Desvantagens } & Poderá constituir um sumidouro para as areias da deriva litoral \\
\hline & & & A operação de dragagem poderá interferir com a navegação \\
\hline & \multirow{3}{*}{$\begin{array}{l}\text { BANCO DA } \\
\text { BARRA }\end{array}$} & & Está mais próximo dos locais de deposiçáo \\
\hline & & vants & Não interfere com a navegação \\
\hline & & Desvantagens & $\begin{array}{l}\text { Susceptível de alterar de forma significativa o padrão de ondulação até à linha de costa, } \\
\text { com consequências negativas sobre a sua protecçáo }\end{array}$ \\
\hline \multirow{7}{*}{ 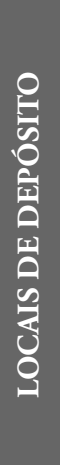 } & \multirow{4}{*}{ Em TERRA } & Vantagens & Maior eficácia da protecção local a curto prazo \\
\hline & & \multirow{3}{*}{ Desvantagens } & Custos de operação superiores \\
\hline & & & Necessita da construção de esporôes caso ocorra em locais onde eles não existam \\
\hline & & & Impactes sobre os ecossistemas dunares muito superiores \\
\hline & \multirow{3}{*}{ No MAR } & \multirow{3}{*}{ Vantagens } & Custos de operaçáo inferiores \\
\hline & & & As operaçōes podem realizar-se por diferentes tipos de dragas \\
\hline & & & $\begin{array}{l}\text { Parte das areias poder-se-á perder para a deriva litoral, diminuindo a eficácia se não } \\
\text { houver a jusante esporóes suficientemente longos para interceptar o transporte }\end{array}$ \\
\hline
\end{tabular}


Tabela 5. Principais critérios utilizados na escolha de soluções de deposição

Table 5. Main criteria used to choose the final deposition solution

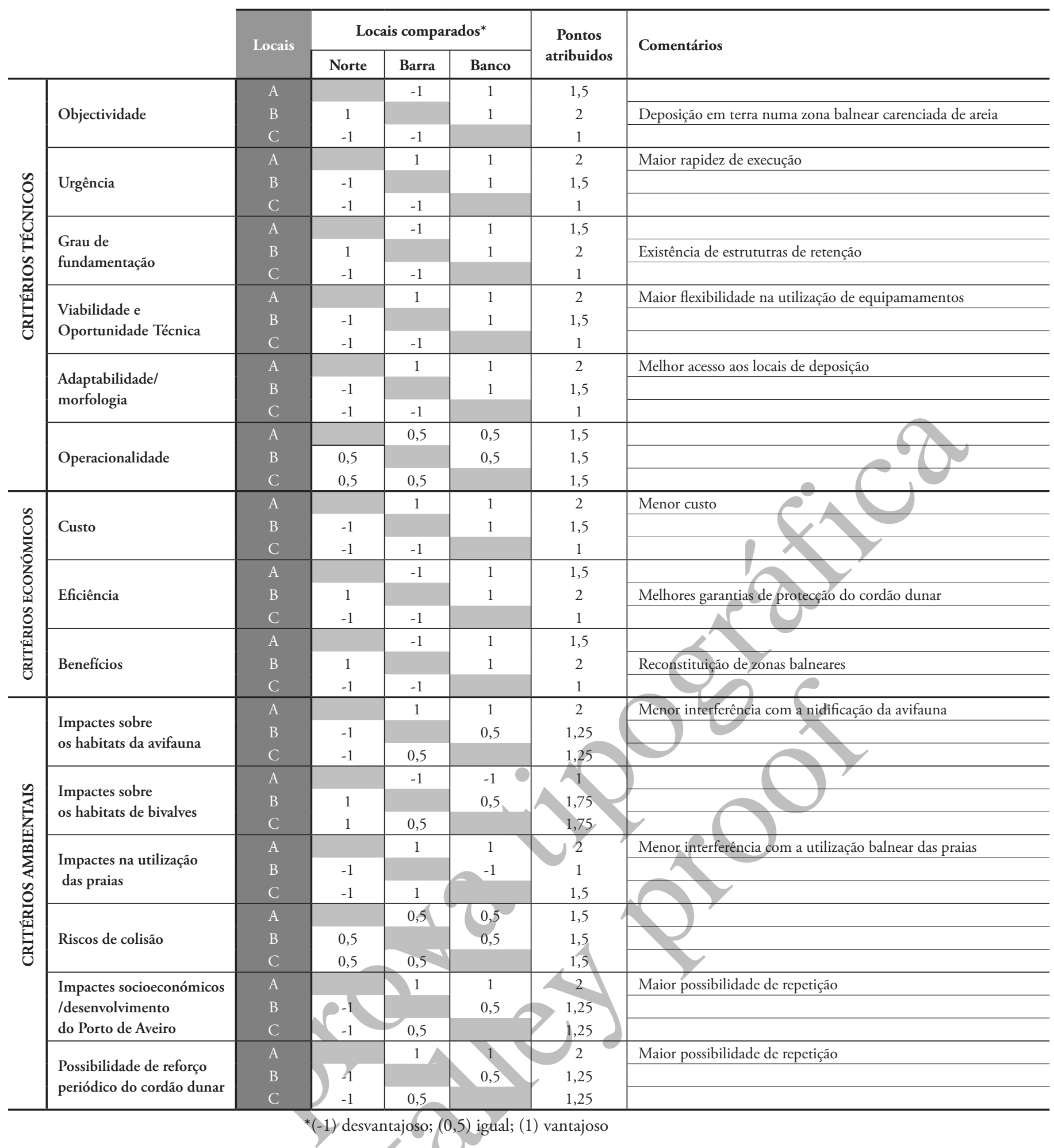

\section{AGRADECIMENTOS}

O estudo apresentado foi suportado pelo IPTM (Instituto Portuário e dos Transportes Marítimos, I.P), a APA (Administração do Porto de Aveiro, S.A) e pelo INAG (Instituto da Água, I.P.). Os autores agradecem os contributos dos técnicos destas entidades, que acompanharam a realização do trabalho. Agradecem ainda os contributos dos revisores e do editor da revista pelos comentários, sugestóes e críticas apresentadas que, em muito, contribuíram para a melhoria do artigo. 


\section{BIBLIOGRAFIA}

Barata, A., Teles, M.; Vieira, J.R. (1996) - Selecção de Ondas Representativas da Agitação Marítima para efeito da Avaliação do Transporte Litoral na Costa de Aveiro. Recursos Hidricos (ISSN: 0870-1741), 17(1):43-74, Lisboa, Portugal.

Cunha, P.P.; Dinis, J.L. (1998) - A erosão nas praias do Cabo Mondego à Figueira da Foz (Portugal centro-oeste), de 1995 a 1998. Territorium (ISSN: 0872-8941), 5:31-50, Coimbra, Portugal.

Dias, J.A.; Ferreira, Ó.; Pereira, A.R. (1994) - Estudo Sintético de Diagnóstico da Geomorfologia e da Dinâmica Sedimentar dos Troços Costeiros entre Espinho e Nazaré. 280 p., ESAMIN / Instituto de Conservação da Natureza, Lisboa, Portugal. Edição electrónica (2005): http://w3.ualg.pt/ -jdias/JAD/ eb_EspinhoNAzaré.html.

Ferreira, O. (1993) - Caracterização dos principais factores condicionantes do balanço sedimentar e da evolução da linha de costa entre Aveiro e o Cabo Mondego. Dissertação de Mestrado, 168 p., Universidade de Lisboa, Portugal. Não publicado.

Hidroprojecto (1994) - Estudos Especializados de Modelação Matemática para a Barra de Aveiro. Relatório Técnico. Elaborado para a Junta Autónoma do Porto de Aveiro, 144 p., Lisboa, Portugal. Não Publicado.

Hidroprojecto (2001) - Monitorização da Ria de Aveiro - Relatório de Calibraçáo do modelo matemático da Ria e caracterização da situação actual (pós - dragagens). Relatório Técnico. Elaborado para a Junta Autónoma do Porto de Aveiro, 17p., Lisboa, Portugal. Não Publicado.

Hidroprojecto (2006) - Estudo da Intervenção na Zona da Barra de Aveiro com Dragagem e Reforço do Cordão Dunar. Nota Técnica, 40p., fectuada para o IPTM, APA e INAG. Lisboa. Portugal. Não Publicado.

Hidroprojecto (2007) - Estudo da Intervenção na Zona da Barra de Aveiro com Dragagem e Reforço do Cordão Dunar. EIA. Efectuado para o IPTM, APA e INAG. 167p., Lisboa. Portugal. Não Publicado.
Instituto Hidrográfico (1990) - Roteiro da Costa de Portugal.

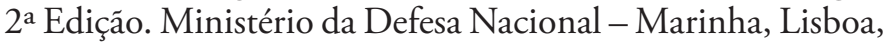
Portugal. ISBN: 9729002177.

Instituto Hidrográfico (2010) - Tabela de Marés 2011. Volume I. Portugal. 192 p., Instituto Hidrográfico, Lisboa, Portugal. ISBN: 9789728486907.

Leendertse, J.J. (1987) - Aspects of SYMSIS2D. A System for Two-Dimensional Flow Computation. Prepared for the US Geological Survey, R-3572-USGS, 80p., The RAND Corporation, Santa Monica, California. ISBN: 0833008390.

Mota-Oliveira I.B. (1990) - Erosão Costeira no Litoral Norte. Consideraçóes sobre a sua Génese e Controlo, Actas do $1^{\circ}$ Simpósio sobre a Proteç̧ão e Revalorização da Faixa Costeira do Minho ao Liz, pp.201-221, Instituto de Hidráulica e Recursos Hídricos, Porto, Portugal.

Pires, H.N.O. (1989) - Alguns Aspectos do Clima de Agitação Maritima de Interesse para a Navegação na Costa de Portugal. 34p., Clima de Portugal, Fascículo XXXVII, vol. 2, Instituto Nacional de Meteorologia e Geofísica (INMG), Lisboa, Portugal.

Plecha, S.M.N. (2004) - Análise da Vulnerabilidade ao Galgamento de um Trecho da Costa Oeste Portuguesa. Relatório de estágio curricular, 36p. Licenciatura em Meteorologia e Oceanografia Física, Universidade de Aveiro e Hidroprojecto, Lisboa, Portugal. Não publicado.

Teixeira, S.B. (1994) - Dinâmica Morfossedimentar da Ria de Aveiro (Portugal). Dissertação de Doutoramento, 396p., Universidade de Lisboa, Portugalı Não publicado.

Teles M.; Barata, A. (1996) - Morfodinâmica da regiāo da Barra de Aveiro. Actas da $5^{a}$ Conferência Nacional sobre Qualidade do Ambiente vol. 1, 361-373, Universidade de Aveiro, Portugal. ISNB: 9725690885.

Van Rijn, L.C. (1989) - Handbook Sediment Transport by Currents and Waves. 2a edição, Delft Hydraulics Laboratory, Delf, Holanda. 